\title{
ASSESSING THE PRUDENCE OF ECONOMIC FORECASTS IN THE EU
}

\author{
G. A. CHRISTODOULAKIS ${ }^{\mathrm{a} *}$ AND E. C. MAMATZAKIS ${ }^{\mathrm{b}}$ \\ a Manchester Business School, Manchester, UK \\ ${ }^{\mathrm{b}}$ Department of Economics, University of Piraeus, Piraeus, Greece
}

\section{SUMMARY}

\begin{abstract}
We estimate the EU Commission loss preferences for major economic forecasts of 12 Member States. Based on a recently proposed method by Elliott, Komunjer and Timmermann (2005) the paper provides evidence of asymmetries in the underlying forecast loss preference of the Commission that tend to vary across Member States. In some cases, our results show that EU forecasts tend to display a rather optimistic picture for main economic variables, e.g. government balance, thus allowing a certain degree of leeway in the fiscal adjustment path towards the medium-term objective of 'close to balance' or 'in surplus' of the recently revised Stability and Growth Pact. Over the period of our sample, 1970-2004, this apparent asymmetry in the underlying loss preferences tends to deter prudent advice over economic policy. Lastly, we provide an analysis on the trade-off between loss and distribution asymmetries, for which simulation results show that the testing method is robust in the presence of skewness. Copyright (c) 2009 John Wiley \& Sons, Ltd.
\end{abstract}

\section{INTRODUCTION}

The European Commission publishes regular forecasts for main economic aggregates in Member States of the European Union (EU). The quality of these forecasts is of particular interest because forecasts prepared by an independent institution like the European Commission would remove political bias from the national forecasts. Lars and Larch (2006) argue that national forecasts suffer from bias as they are politically motivated and a solution would be an independent authority to provide forecasts. They further claim that Commission forecast exercise is unbiased and provide the benchmark that bypasses the hazards from national forecasters, and thereby could be effectively used in the annual assessment of EU economies, especially those economies in an Excessive Deficit Procedure (EDP).

The debate of whether the national or Commission forecasts are more appropriate to use in economic policy exercises is further fuelled by the ongoing economic convergence and the synchronization of business cycles across Member States in the EU. In this context, the reinforcement of statistical criteria for key nominal macroeconomic variables in the recently reformed Pact of Maastricht treaty within the Exchange Rate Mechanism II, the first step towards the adoption of the euro, further strengthens discussions concerning the quality of Commission forecasts.

Furthermore, forecasts in the deficit/GDP ratio have recently attracted significant attention as figures above the threshold value of $3 \%$ would initiate the process of Excessive Deficit Procedure.

\footnotetext{
* Correspondence to: G. A. Christodoulakis, Manchester Business School, Crawford House, Booth Street West, Manchester
} M15 6PB, UK. E-mail: george.christodoulakis@mbs.ac.uk

Copyright (C) 2009 John Wiley \& Sons, Ltd. 
This process could potentially lead to sanctions for the Member States (MSs thereafter) that opt not to take effective action to correct the excessive deficit within the deadlines stated in the reformed Pact. Lars and Larch (2006) raise the point that MSs should use the impartial Commission forecasts to achieve better policy outcomes and avoid procyclical economic stances that could jeopardize the economic stability of the EU, and hamper growth prospects.

Although the quality of economic forecasts of the EU Commission has been the subject of a broad debate in the press, the business community and governments alike during the past decade, there is rather limited academic research in the area (see Artis and Marcellino, 2001; Lars and Larch, 2006). This paper contributes to the literature by assessing an area that has not been dealt with in the literature, namely the examination of asymmetries in the underlying loss function of Commission forecasts. Moreover, this paper applies the methodology of Elliott et al. (2005) to estimate the parameter which controls for the symmetry-asymmetry properties for some key macroeconomic variables over the period 1970-2004. As a further step, conditional on our empirical results, we extend this analysis by solving a theoretical relationship which allows mapping the estimated preference asymmetries on the shape of the subjective density function, as if preferences were symmetric. The estimation concerns year-ahead and current-year forecasts. Our findings show that Commission forecasts display for some MSs optimism for the year-ahead forecasts, whereas for the current year the estimated loss preferences lean towards pessimism, which could be interpreted as a prudent attitude. In addition, we provide an analysis on the tradeoff between loss and distribution asymmetries, for which simulation results show that the testing method is robust in the presence of skewness.

\section{THE TRACK RECORD OF COMMISSION FORECASTS}

Artis and Marcellino (2001) present evidence for the forecast record of the European Commission which places it among the best international organizations such as the IMF and OECD, producing regular forecasts for European countries. Also Keereman (1999) emphasizes the good track record of the Commission's forecasts and the transparency of the whole forecast exercise. Moreover, it appears that the European Commission forecasts make use of all available information, and are based on a bottom-up approach wherever appropriate, e.g. not forecasting directly on the deficit/surplus but rather computing it as the difference between predicted revenues and expenditures. In addition, fiscal forecasts are produced in a framework in which macroeconomic models are an important ingredient, in conjunction with the Commission experts' judgement. Essentially, Commission forecasts can be considered as full information forecasts in terms of employed data and projection methods.

In particular, the European Commission produces annual projections for macroeconomic aggregates for MS twice a year, ${ }^{1}$ in spring and autumn, focusing on the current year and the

\footnotetext{
${ }^{1}$ The Commission's forecasting process involves a considerable amount of human resources of DG II (Directorate General) of the ECFIN (Economy and Finance) and it starts with a position paper, including the monetary assumptions and the outlook for the world economy and international trade. The latter assumptions are considered as external and they are also sent to the capitals to be considered during the national forecasting process. Forecasts based on a judgemental approach are then confronted by the econometric projections of DGII's QUEST model (Roeger and in't Veld, 1997). Also, a separate trade consistency model is used to check bilateral import and export flows and prices and to ensure consistency both at the EU level and at the world level. Towards the end of this process the forecasts are subject to a bilateral discussion between the Commission and the national capitals. As Keereman (1999) states, 'the forecasts have to be considered a technical exercise prepared independently by DG II'.
} 
year-ahead forecasts. For reasons of data availability, we shall consider the EU-12, thus excluding MSs that joined the Union in 1995 and thereafter. The sample size for each MS varies, from 35 data points for founding members to 18 data points for Spain and Portugal, which joined in 1986.

The selection of the series representing forecasts and outcomes is not without importance as it might influence the size and meaning of the forecast error. In order to examine the sensitivity of the forecast performance with respect to the time horizon, two types of forecasts and their associated outcomes are analysed. The current-year forecast is concerned with the quality of the projection made at the beginning of the year for the same year, while the year-ahead forecast deals with the following year. It can be expected that the forecast accuracy is sensitive to the choice of outturn data. Following Kenen and Schwarz (1986) and Artis (1996), the realization data for the current year forecasts, 'first available estimates', are found in the spring forecasts following the year to be forecast. The outturn data for the year ahead forecasts are taken from the autumn forecasts following the year to be forecast, that is, 'first settled estimates'. It is widely considered that the first settled estimate is of greater precision compared with their subsequent revisions, though realizations are continuously revised, if only as a result of new information of methodological changes and of misreporting. ${ }^{2}$ Our year-ahead forecasts are taken from the autumn forecasts of EU Commission.

For the purpose of the current analysis we proceed with an investigation of the underlying loss preference asymmetries of the Commission forecasts for numerous macroeconomic variables, namely government balance, current account, inflation as measured by the private consumption deflator, investment and lastly for unemployment. As mentioned in the Introduction, the loss preference of the Commission forecasts are of interest, especially in light of the reform of the Pact where the criterion of the $3 \%$ deficit is reinforced, at least in the preventive arm of the pact, that is, fiscal targeting over the medium term.

In Figure 1 we present the forecast errors for the EU12 economy, defined in this paper as realization minus the forecast. Thus, for variables such as inflation, a rational economic agent may exhibit, for example, higher aversion to positive forecast errors versus negative ones of the same size, that is, higher cost for under-prediction (versus equal over-prediction), given that the economy is not suffering from disinflation. On the other side, for variables such as government balance, noted with a negative sign in the case of deficit, a rational economic agent may exhibit higher aversion to negative forecast errors versus positive ones of the same size, which reflects higher cost for under-prediction.

It is of interest that for investment forecast errors appear to record negative values, which could be interpreted as over-prediction in periods of recession, is in the late 1990s, thus implying that Commission forecasts for the EU economy have painted at periods a rather rosy picture when indeed recovery seems to be not just yet around the corner. This is also the case during the last years of the sample, when it seems that there had been a dramatic reversal in the forecast error of investment from a high positive forecast error in 2002 to a dramatic decline thereafter. In the case of government balance, note that the deficit would imply negative values so in terms of our analysis a negative forecast error means that those balances would turn out worse than expected. This case is defined as under-prediction, while when the forecast error is positive overprediction in the deficit occurs. Indeed, although on average government balances fluctuate around the value of zero, there exists clear evidence of negative forecast errors for many years, that is,

\footnotetext{
${ }^{2}$ It is worth noting, though, that older data have higher probability to be subjected to revisions, and this would potentially assert an impact on the underlying forecast error through time.
} 

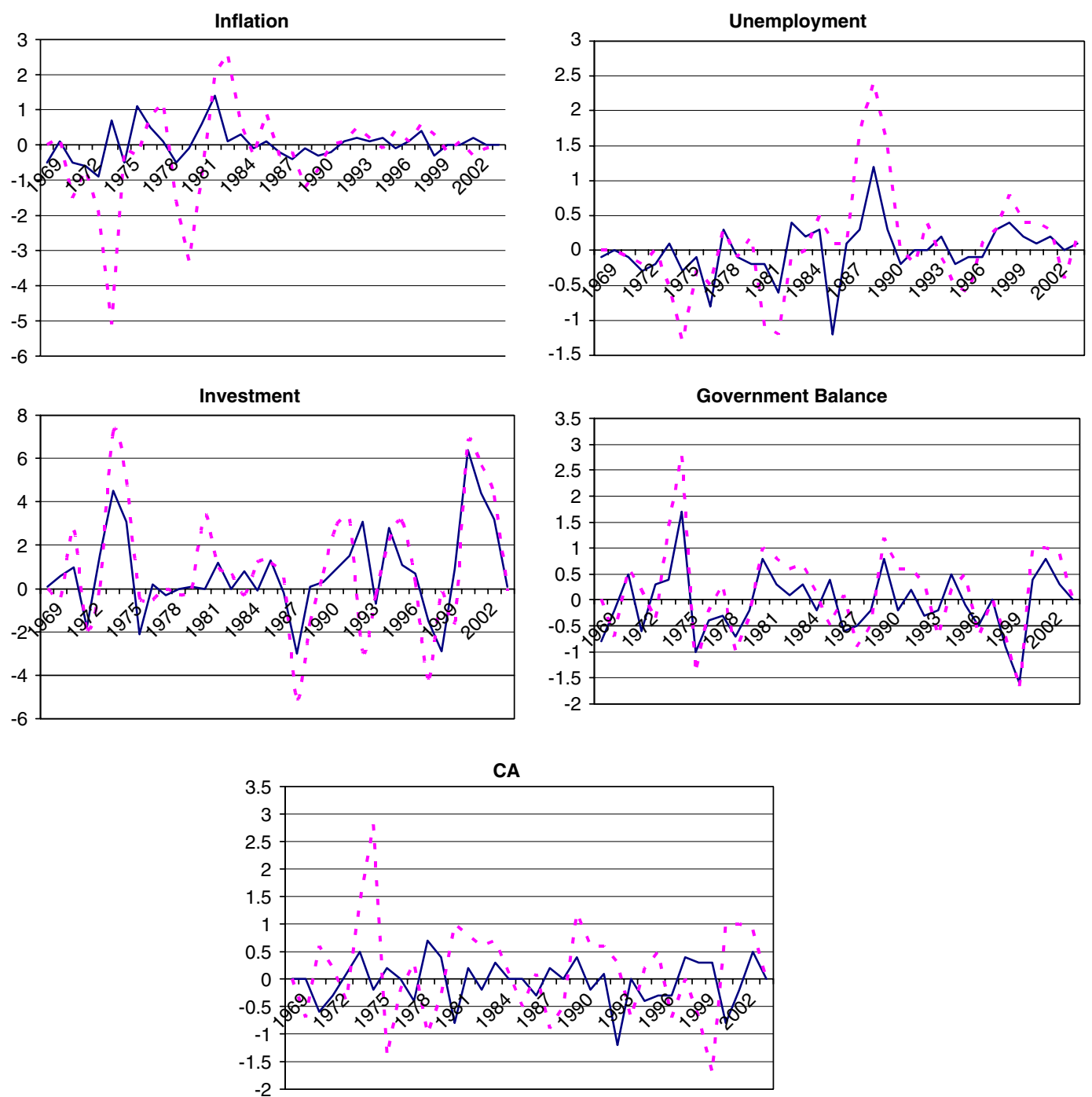

Figure 1. EU12 current-year and year-ahead forecast errors. Solid and dashed lines refer to current-year and year-ahead forecast errors, respectively. This figure is available in color online at www.interscience.wiley. com/journal/jae

under-prediction, especially in the case of year-ahead forecasts. Moreover, it is striking to note that although government balance forecast errors have recorded positive values since 2002, there is a sharp decline in their values thereafter at a period characterized by high fiscal imbalances in all major euro area economies. This picture implies that an asymmetry in the underlying loss preference structure could have taken place in the EU especially within the euro area, and it is directly in contrast with the year prior to the accession in the euro area when rising forecast errors, and thus under-prediction, is depicted by Figure 1. Another interesting and striking finding 
from Figure 1 is the divergence between actual and year-ahead forecasts for our variables, except inflation, since the 1990s. Especially for the government and the current account balances, since 2002 it appears that the forecast error has been higher for the year-ahead forecasts compared with the current year. Although such graphical evidence raises our intuition regarding the existence of possible preference asymmetries, we now turn our attention to more sophisticated evidence developed in the following section.

\section{ESTIMATING THE UNDERLYING ASYMMETRIC PREFERENCES}

Elliott et al. (2005) have recently proposed a widely applicable method ${ }^{3}$ for any frequency data and in this paper we shall follow their paradigm. They consider a flexible loss function of the form

$$
L(p, \alpha) \equiv\left[\alpha+(1-2 \alpha) \mathbf{1}_{\left(Y_{t+1}-f_{t+1}<0\right)}\right]\left|Y_{t+1}-f_{t+1}\right|^{p}
$$

where $Y_{t+1}-f_{t+1}$ is the forecast error, $p=1,2, \alpha \in(0,1)$ and $\mathbf{1}$ is an indicator which takes the value of one if $Y_{t+1}-f_{t+1}<0$ and zero otherwise.

The above function nests the double linear (Lin-Lin) loss for $p=1$ and the double quadratic (Quad-Quad) for $p=2$. If $\alpha=0.5$, then the loss function reduces to that of familiar cases under a linear or quadratic loss function, widely used in prior research on forecast accuracy. If $\alpha>0.5$, however, then over-predictions are less costly to the forecaster. In other words, the analyst has incentives to over-predict the government surplus, say. Our ignorance concerning the forecaster's objectives consists only of not knowing the value of the single parameter $\alpha$. The general idea of recovering a parameter from the data that is most consistent with optimizing behaviour and assessing the extent to which optimality restrictions are satisfied in the data appears first in Hansen and Singleton (1982).

By observing the sequence of forecast errors $\left\{Y_{t+1}-f_{t+1}\right\}$, with $\tau \leq t<T+\tau$, an estimate for $\alpha$ is constructed using a linear instrumental variable estimator $\hat{a}_{T}$, as follows:

$$
\hat{\alpha}=\frac{\left[\frac{1}{\mathrm{~T}} \sum_{t=\tau}^{\mathrm{T}+\tau-1} \mathbf{v}_{t}\left|Y_{t+1}-f_{t+1}\right|^{p-1}\right]^{\prime} \hat{S}^{-1}\left[\frac{1}{\mathrm{~T}} \sum_{t=\tau}^{\mathrm{T}+\tau-1} \mathbf{v}_{t} \mathbf{1}_{(Y t+1-f t+1<0)}\left|Y_{t+1}-f_{t+1}\right|^{p-1}\right]}{\left[\frac{1}{\mathrm{~T}} \sum_{t=\tau}^{\mathrm{T}+\tau-1} \mathbf{v}_{t}\left|Y_{t+1}-f_{t+1}\right|^{p-1}\right]^{\prime} \hat{S}^{-1}\left[\frac{1}{\mathrm{~T}} \sum_{t=\tau}^{\mathrm{T}+\tau-1} \mathbf{v}_{t}\left|Y_{t+1}-f_{t+1}\right|^{p-1}\right]}
$$

where $v_{\mathrm{t}}$ is a $\mathrm{d} \times 1$ vector of instruments which is a subset of the information set used to generate $f$, while $\hat{S}$ is given by

$$
\hat{S}=\frac{1}{\mathrm{~T}} \sum_{t=\tau}^{\mathrm{T}+\tau-1} \mathbf{v}_{t} \mathbf{v}_{t}^{\prime}\left(\mathbf{1}_{\left(Y_{t+1}-f_{t+1}<0\right)}-\hat{\alpha}_{T}\right)^{2}\left|Y_{t+1}-f_{t+1}<0\right|^{2 p-2}
$$

Since $\hat{S}$ depends on $\hat{\alpha}_{T}$, estimation is performed iteratively, assuming $S=I$ in the first iteration to estimate $\hat{\alpha}_{T, 1}$, until convergence. Elliott et al. (2005) show that the estimator of $\hat{\alpha}_{T}$ is asymptotically

\footnotetext{
${ }^{3}$ The first forecast rationality test under asymmetric loss was proposed by Bachelor and Peel (1998) and further extended by Christodoulakis (2005), but their methods are not applicable in our context owing to the low frequency of our dataset. 
normal and construct a $J$-statistic which under the joint null hypothesis of rationality and flexible loss function is distributed as a $\chi^{2}(d-1)$ variable for $d>1$ and takes the form

$$
J=\frac{1}{\mathrm{~T}}\left[\begin{array}{c}
\left(\sum_{t=\tau}^{\mathrm{T}+\tau-1} \mathbf{v}_{t}\left[\mathbf{1}_{\left(Y_{t+1}-f_{t+1}<0\right)}-\hat{a}_{T}\right]\left|Y_{t+1}-f_{t+1}\right|^{p-1}\right)^{\prime} \hat{S}^{-1} \\
\left(\sum_{t=\tau}^{\mathrm{T}+\tau-1} \mathbf{v}_{t}\left[\mathbf{1}_{\left(Y_{t+1}-f_{t+1}<0\right)}-\hat{a}_{T}\right]\left|Y_{t+1}-f_{t+1}\right|^{p-1}\right)
\end{array}\right] \sim \chi_{d-1}^{2}
$$

For robustness, in the empirical analysis we consider the flexible loss function of equation (1) both for $p=1$, i.e. the linear case, and $p=2$, i.e. the quadratic case, using three instruments, in particular a constant, the lagged forecast error, as well as the lagged realization.

A fundamental concern would be whether the estimated loss function structure, irrespective of asymmetries, reflects actual preferences rather than systematic model biases. As shown in the methodology followed hereafter, the loss function reflects actual preferences. Moreover, this method considers the general class of linear predictors of the form

$$
f_{t+1}=\Theta(\alpha)^{\prime} W_{t}
$$

where $\Theta$ is a $K \times 1$ vector of parameters which is an implicit function of $\alpha, W_{t}$ is the full set of factors and are known to the forecaster at time $t$, and $\alpha$ is the loss asymmetry parameter. In the context of asymmetric preferences given in equation (1) of our paper, $f_{t+1}$ is an optimal forecast if and only if the first-order forecast optimality conditions (f.o.c.) are

$$
E\left\lfloor W_{t}\left(\mathbf{1}_{\left(Y_{t+1}-f_{t+1}<0\right)}-\alpha\right)\left|Y_{t+1}-f_{t+1}\right|^{p-1}\right\rfloor=0
$$

If for given $\alpha$ and $p$ the forecaster uses the above condition to determine $f_{t+1}$ (Elliott et al. show that this solution is unique), then for given $f_{t+1}$ it is possible to use the same condition to uniquely 'back out' $\alpha$. In the case of model misspecification, suppose we observe only $V_{t}$ which is a sub-vector of $W_{t}$, and our forecast becomes $f_{t+1}=\tilde{\Theta}(\alpha)^{\prime} V_{t}$. Then, Proposition 1 of Elliott et al. ensures that

$$
E\left\lfloor V_{t}\left(\mathbf{1}_{\left(Y_{t+1}-f_{t+1}<0\right)}-\alpha\right)\left|Y_{t+1}-f_{t+1}\right|^{p-1}\right\rfloor=0
$$

also holds. Then, Lemma 2 of Elliott et al. proves that the above condition is sufficient to identify $\alpha$. Thus, even under model misspecification, the f.o.c. should hold. Our GMM estimator locates the unique $a$ that minimizes the variation of the f.o.c. under model misspecification. This explains the logic under which this analysis deals with the issue of misspecification (see also Elliott et al., 2005, section 5. In this respect, we have performed robustness checks by using subsets of our three instruments which yielded close estimates for the parameters but with inferior standard errors, while impairing the speed of algorithm convergence. As Elliott et al. suggest at the end of section 3 of their paper, 'outside this situation, one could attempt to use data-based methods for selection of moment conditions using criteria such as those proposed by Donald and Newey (2001), replacing their MSE loss with our loss L in (1) evaluated at ( $p, \hat{\alpha})$ where $\hat{\alpha}$ is a consistent estimate of $\alpha . '$

\subsection{Empirical Results for Asymmetric Preferences}

In the following tables we present our estimates of $\alpha$, and the $J$-statistics for the estimated $\alpha$, for the current year and year-ahead forecasts for our variables when the loss function is linear, that is, 
$p$ in equation (1) takes the value of 1 . In addition, we provide estimates for the $J$-statistic, under the imposed null that $\alpha$ takes the values of $0.2,0.5$, and 0.8 , that serve as additional tests against various hypotheses of prudence. Our results for asymmetric quadratic loss $(p=2)$ are provided in the Appendix.

In Table I we present our results for inflation both for the current and year-ahead forecasts. In the first column we present the estimated values for the loss parameter estimate of $\alpha$ for currentyear forecasts, whereas in the second column we report the corresponding standard errors. In the third column, we report the $J$-statistic for the estimated $\alpha$ of the first column. In columns 4-6 we present the $J$-statistic for the imposed null hypothesis that $\alpha=0.2,0.5$, and 0.8 . The same structure applies for the right-hand side of the table, which refers to year-ahead forecast. We observe that for year-ahead forecasts the majority of the MSs exhibit parameter estimates which are not statistically different from 0.5 , implying that there exists a tendency of a symmetric loss preference function in the Commission forecasts. Notable exceptions are the cases of Spain, Italy and Portugal, for which the Commission seems to exhibit statistically significant asymmetric preferences towards optimism $(\alpha<0.5)$, while for UK and Ireland preferences are shown to be pessimistic $(\alpha>0.5)$ and statistically significant. As long as prudent inflation forecasting assigns higher costs to optimism that is under-forecasting rather than over-forecasting, we observe a failure to apply a loss function that accommodates prudent preferences for these MSs. Our results appear to confirm that for Spain, Italy and Portugal higher inflation rates than the EU average were exhibited in the 1970s and 1980s, which were also reflected as under-prediction, whereas since the late 1990s there was a shift to reduce inflation differentials so as to reach the average of the best three performers in the EU, as part of their nominal convergence to the Maastricht criteria prior to their accession into the euro area. This shift is depicted in Figure 1 as there appears to be a correction towards symmetry of the loss preference function, where the forecast error has drifted closer to zero since the mid 1990s. It is worth noting though that clearly higher inflation rates than the euro area average still pertain in those MSs, highlighting the differences across MSs in terms of competitiveness and structure mainly in service markets. This is particularly valid for the case

Table I. Inflation under asymmetric linear loss function

\begin{tabular}{|c|c|c|c|c|c|c|c|c|c|c|c|c|}
\hline \multicolumn{7}{|c|}{ Current year } & \multicolumn{6}{|c|}{ Year ahead } \\
\hline & $\hat{\alpha}$ & SE & $J_{\hat{\alpha}}$ & $J_{\alpha=0.2}$ & $J_{\alpha=0.5}$ & $J_{\alpha=0.8}$ & $\hat{\alpha}$ & SE & $J_{\hat{\alpha}}$ & $J_{\alpha=0.2}$ & $J_{\alpha=0.5}$ & $J_{\alpha=0.8}$ \\
\hline Bel. & 0.42 & 0.08 & 1.17 & 6.44 & 1.87 & 12.75 & 0.59 & 0.08 & 6.32 & 14.46 & 8.06 & 7.81 \\
\hline Den. & 0.42 & 0.09 & 0.33 & 5.19 & 1.15 & 11.61 & 0.41 & 0.09 & 3.40 & 6.88 & 3.36 & 10.87 \\
\hline Ger. & 0.49 & 0.08 & 0.25 & 8.69 & 0.27 & 9.95 & 0.68 & 0.08 & 5.61 & 15.41 & 8.36 & 6.25 \\
\hline Gr. & 0.47 & 0.10 & 3.59 & 6.30 & 3.58 & 7.31 & 0.36 & 0.10 & 0.65 & 2.48 & 2.36 & 10.01 \\
\hline Sp. & 0.23 & 0.10 & 3.48 & 3.51 & 5.76 & 9.44 & 0.04 & 0.04 & 3.75 & 6.89 & 7.34 & 11.00 \\
\hline Fr. & 0.43 & 0.08 & 0.64 & 6.31 & 1.37 & 12.71 & 0.42 & 0.08 & 4.26 & 8.10 & 4.31 & 12.12 \\
\hline Ire. & 0.56 & 0.09 & 3.41 & 11.64 & 4.12 & 6.97 & 0.69 & 0.08 & 4.43 & 15.09 & 8.74 & 4.77 \\
\hline Ital & 0.27 & 0.08 & 3.32 & 3.64 & 9.22 & 18.79 & 0.20 & 0.07 & 0.06 & 0.07 & 11.79 & 23.24 \\
\hline Lux. & 0.48 & 0.08 & 5.62 & 9.51 & 5.80 & 11.50 & 0.54 & 0.09 & 4.66 & 11.24 & 4.90 & 8.61 \\
\hline Neth. & 0.48 & 0.08 & 3.49 & 9.23 & 3.54 & 10.56 & 0.54 & 0.09 & 4.00 & 10.90 & 4.00 & 8.85 \\
\hline Port. & 0.04 & 0.03 & 2.75 & 7.07 & 9.57 & 13.44 & 0.33 & 0.11 & 1.26 & 2.63 & 2.12 & 7.97 \\
\hline UK & 0.59 & 0.09 & 1.48 & 11.68 & 2.06 & 5.66 & 0.62 & 0.09 & 2.79 & 12.53 & 4.46 & 5.01 \\
\hline EU & 0.48 & 0.08 & 3.53 & 9.17 & 3.62 & 10.71 & 0.36 & 0.08 & 6.08 & 7.73 & 6.56 & 13.70 \\
\hline
\end{tabular}

Note: Estimates are based on $D=3$ instruments. $J$-statistics are distributed as $\chi^{2}(D-1)$ or $J_{\hat{\alpha}}$ and $\chi^{2}(D)$ for the remaining $J$. 
of Italy, Greece and Portugal, as the $J$-statistics clearly show that the null hypothesis of a highly asymmetric and imprudent forecast, that is imposing $\alpha=0.2$, cannot be rejected for the year-ahead forecasts. Similar results are reported in the Appendix for the case of the quadratic loss preference function. Preferences for current-year forecasts show a tendency towards symmetry, although the cases of Spain, Italy and Portugal still uncover statistically significant optimistic preferences.

Our results for unemployment in Table II show that the underlying loss function of the Commission year-ahead forecast is symmetric for most of the MSs, as $\alpha$ takes a value of around 0.5. However, for the UK, Portugal and Ireland, the forecast preferences exhibit higher aversion to under-prediction, which may reflect attempts to compensate for the concern over the structural nature of high unemployment. These findings are also supported by the respective $J$-statistics, which tend not to reject the null of symmetry for the majority of cases except for the UK, Portugal, Ireland and Luxemburg. For current-year forecasts the picture of prudence remains for the UK and Portugal and extends to Spain, but Belgium and Germany drift towards optimism. Similar results apply in the case of the asymmetric quadratic loss function.

Next, we turn our attention to government balance in Table III, which is the predominant criterion of convergence prior to entry into the euro area. For year-ahead forecasts, our results reveal a picture of rather symmetric preferences since the majority of estimates are not statistically different from 0.5, with the exception of Luxemburg and Portugal, which exhibit pessimistic preferences. On the other side, for Greece our analysis reveals statistically significant optimistic preferences. For current-year forecasts, this picture improves massively towards prudence since for nine out of 12 cases the commission revises its preference parameters to values that are statistically smaller than 0.5. Notable cases are Belgium, Greece, Ireland and Germany, for which the commission revised its year-ahead symmetric and optimistic preferences respectively towards pessimism for current-year forecasts. These results have some economic policy implications given that Belgium, Greece and Italy are MSs with a high debt ratio to GDP; thus under-projecting their deficits impairs a sustainability analysis of their fiscal balances. Similar but weaker criticism applies to more MSs for which the Commission exhibits

Table II. Unemployment under asymmetric linear loss function

\begin{tabular}{|c|c|c|c|c|c|c|c|c|c|c|c|c|}
\hline \multicolumn{7}{|c|}{ Current year } & \multicolumn{6}{|c|}{ Year ahead } \\
\hline & $\hat{\alpha}$ & SE & $J_{\hat{\alpha}}$ & $J_{\alpha=0.2}$ & $J_{\alpha=0.5}$ & $J_{\alpha=0.8}$ & $\hat{\alpha}$ & SE & $J_{\hat{\alpha}}$ & $J_{\alpha=0.2}$ & $J_{\alpha=0.5}$ & $J_{\alpha=0.8}$ \\
\hline Bel. & 0.19 & 0.07 & 11.79 & 11.88 & 13.31 & 15.35 & 0.56 & 0.09 & 12.18 & 12.08 & 12.30 & 11.34 \\
\hline Den. & 0.44 & 0.09 & 2.90 & 7.13 & 3.02 & 10.51 & 0.45 & 0.09 & 5.49 & 8.29 & 5.35 & 9.94 \\
\hline Ger. & 0.31 & 0.08 & 8.42 & 9.03 & 7.80 & 14.57 & 0.52 & 0.09 & 3.16 & 9.78 & 3.11 & 9.05 \\
\hline Gr. & 0.58 & 0.10 & 1.61 & 8.59 & 2.27 & 4.51 & 0.45 & 0.11 & 0.27 & 4.61 & 0.46 & 7.19 \\
\hline Sp. & 0.78 & 0.10 & 1.96 & 10.61 & 5.96 & 1.95 & 0.54 & 0.12 & 2.17 & 5.68 & 2.33 & 4.24 \\
\hline Fr. & 0.38 & 0.08 & 4.40 & 6.66 & 5.38 & 13.56 & 0.45 & 0.09 & 1.82 & 7.27 & 2.05 & 10.95 \\
\hline Ire. & 0.60 & 0.09 & 3.02 & 11.88 & 3.65 & 6.02 & 0.89 & 0.06 & 7.22 & 16.57 & 9.17 & 7.88 \\
\hline Ital & 0.49 & 0.08 & 0.16 & 8.65 & 0.19 & 9.94 & 0.48 & 0.09 & 2.83 & 8.66 & 2.84 & 9.82 \\
\hline Lux. & 0.48 & 0.09 & 0.10 & 7.05 & 0.13 & 8.36 & 0.27 & 0.08 & 5.15 & 4.94 & 10.63 & 15.02 \\
\hline Neth. & 0.58 & 0.08 & 2.66 & 12.90 & 3.25 & 6.90 & 0.60 & 0.09 & 3.65 & 12.49 & 4.24 & 6.71 \\
\hline Port. & 0.85 & 0.08 & 3.30 & 10.48 & 5.53 & 3.45 & 0.89 & 0.08 & 5.28 & 8.15 & 4.46 & 5.42 \\
\hline UK & 0.70 & 0.08 & 1.39 & 15.91 & 5.03 & 2.69 & 0.66 & 0.09 & 5.58 & 12.77 & 7.05 & 6.21 \\
\hline EU & 0.43 & 0.08 & 6.71 & 9.42 & 6.53 & 12.03 & 0.47 & 0.09 & 7.87 & 10.57 & 7.69 & 10.58 \\
\hline
\end{tabular}

Note: Estimates are based on $D=3$ instruments. $J$-statistics are distributed as $\chi^{2}(D-1)$ or $J_{\hat{\alpha}}$ and $\chi^{2}(D)$ for the remaining $J$. 
Table III. Government balance under asymmetric linear loss function

\begin{tabular}{|c|c|c|c|c|c|c|c|c|c|c|c|c|}
\hline \multicolumn{7}{|c|}{ Current year } & \multicolumn{6}{|c|}{ Year ahead } \\
\hline & $\hat{\alpha}$ & SE & $J_{\hat{\alpha}}$ & $J_{\alpha=0.2}$ & $J_{\alpha=0.5}$ & $J_{\alpha=0.8}$ & $\hat{\alpha}$ & SE & $J_{\hat{\alpha}}$ & $J_{\alpha=0.2}$ & $J_{\alpha=0.5}$ & $J_{\alpha=0.8}$ \\
\hline Bel. & 0.31 & 0.08 & 4.59 & 7.80 & 4.63 & 15.03 & 0.61 & 0.08 & 0.63 & 13.56 & 2.16 & 4.65 \\
\hline Den. & 0.63 & 0.09 & 3.96 & 11.27 & 5.51 & 5.16 & 0.60 & 0.09 & 5.92 & 12.27 & 7.77 & 6.46 \\
\hline Ger. & 0.08 & 0.05 & 4.97 & 8.61 & 18.12 & 24.80 & 0.54 & 0.09 & 3.39 & 10.88 & 3.52 & 8.43 \\
\hline Gr. & 0.05 & 0.01 & 4.98 & 10.75 & 10.54 & 14.55 & 0.71 & 0.10 & 4.01 & 10.68 & 6.76 & 3.97 \\
\hline Sp. & 0.44 & 0.12 & 0.58 & 3.71 & 0.74 & 6.15 & 0.53 & 0.12 & 0.33 & 5.20 & 0.38 & 3.93 \\
\hline Fr. & 0.48 & 0.08 & 1.88 & 9.33 & 1.85 & 10.13 & 0.47 & 0.09 & 1.21 & 7.94 & 1.34 & 10.51 \\
\hline Ire. & 0.25 & 0.08 & 4.88 & 4.91 & 7.89 & 15.22 & 0.39 & 0.09 & 1.70 & 4.74 & 2.98 & 12.22 \\
\hline Ital & 0.45 & 0.08 & 3.34 & 8.20 & 3.50 & 11.67 & 0.57 & 0.09 & 1.66 & 11.96 & 2.24 & 6.81 \\
\hline Lux. & 0.12 & 0.06 & 1.89 & 2.85 & 14.12 & 22.32 & 0.24 & 0.08 & 1.86 & 2.07 & 7.18 & 16.87 \\
\hline Neth. & 0.34 & 0.08 & 0.69 & 3.18 & 4.10 & 16.89 & 0.40 & 0.08 & 2.08 & 5.94 & 3.01 & 13.26 \\
\hline Port. & 0.19 & 0.09 & 0.85 & 0.85 & 6.17 & 11.89 & 0.25 & 0.11 & 3.49 & 3.54 & 4.15 & 8.14 \\
\hline UK & 0.48 & 0.09 & 1.64 & 7.81 & 1.71 & 9.22 & 0.58 & 0.09 & 2.42 & 10.93 & 2.97 & 6.03 \\
\hline EU & 0.45 & 0.08 & 1.58 & 7.67 & 1.87 & 11.51 & 0.62 & 0.08 & 0.52 & 14.49 & 2.33 & 4.39 \\
\hline
\end{tabular}

Note: Estimates are based on $D=3$ instruments. $J$-statistics are distributed as $\chi^{2}(D-1)$ or $J_{\hat{\alpha}}$ and $\chi^{2}(D)$ for the remaining $J$.

symmetric loss preferences, instead of being more prudent in its underlying loss preference function as depicted by $J_{\alpha=0.2}$. In the case of a quadratic loss preference function (see Table A. III) a similar picture emerges, though for year-ahead forecasts the results for $\alpha$ clearly show that there exists less prudence also in the case of France. Thus, overall, our findings argue that in the case of government balance - the basic nominal criterion for initiating the excessive deficit procedure - the Commission forecasts appear to allow for some leeway against breaching the threshold value, especially for those MSs that were not the best performers in the past.

Table IV presents estimates of the asymmetry parameter $\alpha$ for investment, a variable of great importance, albeit with an underlying data-generating process that is subject to considerable uncertainty. For year-ahead forecasts the Commission is shown to exhibit optimistic preferences for Germany, Greece, Spain, Portugal and the UK. Preferences are shown to be symmetric for the remaining MSs with the notable exception of Netherlands, for which the preference parameter shows a statistically significant pessimism.

Current-year forecast preferences tend to show a significant change as compared to year-ahead preferences, where symmetry tends to pessimism and optimism tends to symmetry. Exceptions are the cases of UK and Greece, for which the Commission preferences remain optimistic. A similar picture emerges when the loss preference function is quadratic. These results indicate that for the majority of MSs investment under-prediction is more costly than over-prediction for year-ahead forecasts, while this result tends to be diminished for current-year forecasts.

Finally, for the case of current account we present our results in Table V. Our estimates for $a$ and $J$-statistic for year-ahead forecasts suggest that preferences were optimistic for France, Italy, Greece and Portugal. For the remaining MSs preferences are not statistically different from symmetry, while for the UK and the EU averages are shown to be prudent. Turning our attention to current-year forecasts, we observe that most cases are close to symmetry, for Italy, Greece and Spain preferences remain optimistic and for Germany and Ireland preferences changed to prudence. 
Table IV. Investment under asymmetric linear loss function

\begin{tabular}{|c|c|c|c|c|c|c|c|c|c|c|c|c|}
\hline \multicolumn{7}{|c|}{ Current year } & \multicolumn{6}{|c|}{ Year ahead } \\
\hline & $\hat{\alpha}$ & SE & $J_{\hat{\alpha}}$ & $J_{\alpha=0.2}$ & $J_{\alpha=0.5}$ & $J_{\alpha=0.8}$ & $\hat{\alpha}$ & SE & $J_{\hat{\alpha}}$ & $J_{\alpha=0.2}$ & $J_{\alpha=0.5}$ & $J_{\alpha=0.8}$ \\
\hline Bel. & 0.58 & 0.08 & 0.84 & 12.71 & 1.54 & 6.37 & 0.56 & 0.09 & 0.48 & 11.71 & 0.90 & 6.66 \\
\hline Den. & 0.24 & 0.08 & 2.98 & 3.55 & 6.54 & 17.34 & 0.42 & 0.09 & 1.79 & 6.36 & 2.11 & 10.80 \\
\hline Ger. & 0.56 & 0.08 & 5.03 & 11.90 & 5.09 & 8.84 & 0.64 & 0.08 & 3.00 & 14.61 & 4.09 & 5.62 \\
\hline Gr. & 0.62 & 0.10 & 1.25 & 9.61 & 2.33 & 3.44 & 0.64 & 0.10 & 0.62 & 9.98 & 2.20 & 2.52 \\
\hline $\mathrm{Sp}$. & 0.14 & 0.08 & 6.22 & 6.38 & 4.87 & 7.81 & 0.62 & 0.12 & 2.24 & 6.95 & 3.09 & 3.23 \\
\hline Fr. & 0.64 & 0.08 & 1.85 & 15.60 & 4.17 & 4.52 & 0.58 & 0.08 & 4.02 & 12.08 & 4.20 & 7.69 \\
\hline Ire. & 0.34 & 0.08 & 4.83 & 6.00 & 5.66 & 13.33 & 0.50 & 0.09 & 2.59 & 8.32 & 2.59 & 8.61 \\
\hline Ital & 0.60 & 0.08 & 0.44 & 14.05 & 1.83 & 5.13 & 0.59 & 0.08 & 0.51 & 13.14 & 1.65 & 5.42 \\
\hline Lux. & 0.35 & 0.09 & 4.28 & 5.25 & 5.80 & 12.05 & 0.44 & 0.10 & 0.27 & 5.32 & 0.60 & 9.18 \\
\hline Neth. & 0.39 & 0.08 & 0.95 & 5.25 & 2.42 & 14.15 & 0.09 & 0.05 & 4.80 & 6.44 & 14.14 & 23.35 \\
\hline Port. & 0.56 & 0.12 & 0.38 & 6.12 & 0.54 & 3.72 & 0.76 & 0.10 & 1.67 & 9.50 & 4.48 & 1.73 \\
\hline UK & 0.66 & 0.09 & 1.44 & 14.47 & 3.76 & 3.57 & 0.64 & 0.09 & 1.20 & 13.53 & 3.32 & 3.61 \\
\hline EU & 0.66 & 0.08 & 0.81 & 16.89 & 4.06 & 3.38 & 0.57 & 0.08 & 2.78 & 12.00 & 3.18 & 7.20 \\
\hline
\end{tabular}

Note: Estimates are based on $D=3$ instruments. $J$-statistics are distributed as $\chi^{2}(D-1)$ or $J_{\hat{\alpha}}$ and $\chi^{2}(D)$ for the remaining $J$.

Table V. Current account under asymmetric linear loss function

\begin{tabular}{|c|c|c|c|c|c|c|c|c|c|c|c|c|}
\hline \multicolumn{7}{|c|}{ Current year } & \multicolumn{6}{|c|}{ Year ahead } \\
\hline & $\hat{\alpha}$ & SE & $J_{\hat{\alpha}}$ & $J_{\alpha=0.2}$ & $J_{\alpha=0.5}$ & $J_{\alpha=0.8}$ & $\hat{\alpha}$ & SE & $J_{\hat{\alpha}}$ & $J_{\alpha=0.2}$ & $J_{\alpha=0.5}$ & $J_{\alpha=0.8}$ \\
\hline Bel. & 0.48 & 0.09 & 4.93 & 9.56 & 4.83 & 10.06 & 0.58 & 0.09 & 7.34 & 12.48 & 8.07 & 8.62 \\
\hline Den. & 0.50 & 0.09 & 0.76 & 8.60 & 0.76 & 8.60 & 0.46 & 0.09 & 1.17 & 6.99 & 1.27 & 9.41 \\
\hline Ger. & 0.36 & 0.08 & 0.11 & 3.46 & 2.56 & 14.91 & 0.41 & 0.09 & 2.46 & 6.34 & 3.10 & 12.35 \\
\hline Gr. & 0.80 & 0.09 & 4.23 & 11.54 & 5.44 & 4.25 & 0.61 & 0.10 & 1.64 & 8.60 & 1.87 & 4.54 \\
\hline Sp. & 0.92 & 0.06 & 5.46 & 9.23 & 5.46 & 6.01 & 0.42 & 0.12 & 5.55 & 5.04 & 6.35 & 7.21 \\
\hline Fr. & 0.45 & 0.09 & 0.85 & 7.04 & 1.10 & 10.82 & 0.64 & 0.08 & 4.19 & 13.77 & 4.83 & 6.30 \\
\hline Ire. & 0.34 & 0.09 & 4.70 & 5.80 & 5.93 & 13.39 & 0.46 & 0.09 & 1.35 & 7.00 & 1.44 & 9.42 \\
\hline Ital & 0.69 & 0.08 & 2.03 & 16.50 & 5.66 & 3.32 & 0.67 & 0.08 & 3.19 & 15.07 & 4.79 & 4.96 \\
\hline Lux. & 0.41 & 0.10 & 1.30 & 5.18 & 1.62 & 9.65 & 0.45 & 0.10 & 1.87 & 5.54 & 1.99 & 7.93 \\
\hline Neth. & 0.40 & 0.09 & 3.63 & 6.50 & 4.72 & 12.78 & 0.55 & 0.09 & 11.41 & 12.30 & 11.79 & 10.61 \\
\hline Port. & 0.50 & 0.12 & 3.79 & 5.39 & 3.79 & 5.67 & 0.70 & 0.11 & 2.23 & 8.23 & 4.06 & 2.49 \\
\hline UK & 0.44 & 0.09 & 2.52 & 7.20 & 2.56 & 10.42 & 0.33 & 0.09 & 0.34 & 2.37 & 3.63 & 14.87 \\
\hline EU & 0.41 & 0.09 & 2.25 & 6.29 & 2.89 & 12.33 & 0.20 & 0.07 & 10.72 & 10.76 & 15.70 & 15.75 \\
\hline
\end{tabular}

Note: Estimates are based on $D=3$ instruments. $J$-statistics are distributed as $\chi^{2}(D-1)$ or $J_{\hat{\alpha}}$ and $\chi^{2}(D)$ for the remaining $J$.

Our estimation results in Tables $\mathrm{I}-\mathrm{V}$ are based on a set of three instruments, in particular a constant, the lagged forecast error and the lagged realization. Given that the choice of instruments may alter the asymptotic variance of $\hat{\alpha}_{T}$, one should choose instruments so that hypothesis testing over the existence of symmetric versus asymmetric loss is not affected. As in Elliott et al. (2005), for robustness of our empirical findings we perform further estimations using three additional alternative sets of instruments, that is: (i) a constant; (ii) a constant and the lagged forecast error; and (iii) a constant and the lagged realization. We report our results in Tables B. I-V in the Appendix. We do not include more than three instruments due to the sample size. Our findings 
show that the choice of set of instruments does not affect the interpretation of the results as reported in this section.

Summing up, we observe a tendency to project optimistic year-ahead macroeconomic developments to a varying degree for different MSs. Such optimistic estimates are justified on the basis of preference parameters that are statistically equal or larger (smaller) for such variables as current account, investment and government balance (inflation and unemployment) as well as the corresponding $J$-statistics. As current-year forecasts essentially constitute a revision of year-ahead forecasts, our estimates for the former indicate that optimism tends to be reduced towards prudence. In particular, it is often the case that for certain MSs optimistic or symmetric year-ahead preferences turn to symmetric or pessimistic current-year preferences, respectively. In some cases, asymmetric preferences for large MSs may influence the structure of estimated Commission preferences for the EU12 as a whole. In general, this result is of considerable statistical significance, as the $J$-statistics show.

A general inspection of our dataset reveals a persistent clustering of forecast error signs over time for certain MSs, Given that the Commission's forecasts are judgemental rather than modelbased, episodic data would not be possible to bias subsequent forecasts. Moreover, under prudent forecasting one would expect the presence of negative episodic events to further exacerbate the size of particular forecast errors rather than to cause persistent clustering of forecast error signs.

Furthermore, our empirical evidence suggests that the Commission's forecast preferences are rather diverse across MSs. Since the concept of prudence reflects a certain degree of pessimism in the loss preferences, our results suggest that such an attitude is not always present and sometimes is reversed in the Commission's forecasts. This becomes even more alarming when these forecasts refer to MSs in Excessive Deficit Procedure.

\section{MAPPING ESTIMATED ASYMMETRIES ONTO SUBJECTIVE NON-NORMALITY}

In the previous section we presented empirical evidence on the asymmetries of forecast loss preference structure of a major institutional forecaster: the European Commission. However, as described in Section 2, its forecasting process is to a large extent judgemental and does not explicitly take into account the form of a loss function. Indeed, we observed estimated preference asymmetries which in some cases contrast with what is meant to be a prudent attitude.

In a recent paper, Christodoulakis (2005) shows that optimal forecasts under both asymmetric loss and non-normality exhibit trade-offs between preference and density asymmetries. For example, an optimal forecast could remain unchanged by compensating less preference conservatism with more density skewness and vice versa. Another way of looking at it would be to consider what is known as the peso problem, ${ }^{4}$ a phenomenon that may occur at a time when although the loss preferences may be symmetric there is a very small ex ante probability of an extreme event (e.g. sharp devaluation). Furthermore, the literature of stock market behaviour has benefited substantially in explaining empirical stylized facts, where it is shown that the peso problem hypothesis has much more far-reaching implications that the standard approaches (see, for example, Rietz, 1988; Brown et al., 1995; Danthine and Donaldson, 1999; Goetzmann and Jorion, 1999a,b; Veronesi, 2004). Our analysis in this section does not offer an alternative model to that in Section 3, but

\footnotetext{
${ }^{4}$ We would like to thank an anonymous referee for bringing this interpretation to our attention. 
rather solves a theoretical relationship, which is conditional to our empirical results, and highlights the peso problem interpretation.

We ask the following question: conditional on the existence of our estimated preference asymmetries, would it be possible to generate the observed forecasts under symmetric preferences and non-normal distributions? We show that, indeed, it is possible to maintain the assumption of symmetric loss, while mapping any preference asymmetries on a subjective non-normal distribution. This is intuitively appealing in that practitioners often think in terms of likelihood rather than loss functions. Thus, if preference asymmetries can be estimated, one could then 'back out' the implied (subjective) skewness as if preferences were symmetric. In the following, for analytical and computational convenience, we shall capture skewness effects through a truncated density.

In particular, in this section we intend to address whether there would be an implicit belief about the likelihood of extreme positive or negative changes for the variable under investigation if a forecaster has a loss function that may be symmetric and linear. The mapping of preferences asymmetries to subjective distributions is derived as a special case of the general form of loss function from equation (1) that takes the asymmetric linear loss of the form

$$
L(p, \alpha) \equiv \begin{cases}(1-\alpha)\left|Y_{t+1}-f_{t+1}\right| & \text { for }\left(Y_{t+1}-f_{t+1}\right)<0 \\ \alpha\left|Y_{t+1}-f_{t+1}\right| & \text { for }\left(Y_{t+1}-f_{t+1}\right) \geq 0\end{cases}
$$

It can be shown that under normality optimization of (8) yields an optimal forecast of the form

$$
f_{t+1}=\mu_{t+1}+\Phi^{-1}(\alpha) \sigma
$$

where $\mu$ and $\sigma$ are the conditional mean and variance respectively, $\Phi^{-1}()$ is the inverse standard normal distribution, $\Phi^{-1}(\alpha)<0$ for $\alpha E(0,0.5)$, which implies there exists higher aversion to over-prediction, whereas $\Phi^{-1}(\alpha)>0$ for $\alpha E(0.5,1)$.

Consider a forecaster who exhibits symmetric preferences with respect to forecast errors but he or she has beliefs about the likelihood of extreme positive or negative values of the variable to be forecast, e.g. $Y_{t+1}<\beta$ or $Y_{t+1}>\beta$. Christodoulakis (2006) shows that if $\left.Y_{t+1}\right|_{Y_{t+1}<\beta} \sim N\left(\mu_{t+1}, \sigma^{2}\right)$ or $\left.Y_{t+1}\right|_{Y_{t+1}>\beta} \sim N\left(\mu_{t+1}, \sigma^{2}\right)$, then the optimal forecast under symmetric loss preferences is given by the mean of the truncated distribution, which takes the form

$$
\begin{aligned}
& E_{t}\left(\left.Y_{t+1}\right|_{Y_{t+1}<\beta}\right)=\mu_{t+1}-\frac{\varphi(\chi)}{\Phi(\chi)} \sigma \\
& E_{t}\left(\left.Y_{t+1}\right|_{Y_{t+1}>\beta}\right)=\mu_{t+1}+\frac{\phi(\kappa)}{1-\Phi(\kappa)} \sigma
\end{aligned}
$$

where $\kappa=\frac{\beta-\mu_{t+1}}{\sigma}$, and $\varphi(\chi), \Phi(\chi)$ are the density and cumulative standard normal density, respectively. Note the similarity of equations (9) and $(9 a, b)$, which both propose an optimal forecast which is composed of the conditional mean plus a weighted component of standard deviation, the weights being a function of the preference parameter. It is then straightforward to examine the equivalence of the two optimal predictors. From equations (8), (9a) and (9b) we 
obtain

$$
\Phi^{-1}(\alpha)=-\frac{\varphi\left(\frac{\beta-\mu_{t+1}}{\sigma}\right)}{\Phi\left(\frac{\beta-\mu_{t+1}}{\sigma}\right)} \quad \text { for } \alpha E[0,0.5)
$$

and

$$
\Phi^{-1}(\alpha)=\frac{\varphi\left(\frac{\beta-\mu_{t+1}}{\sigma}\right)}{1-\Phi\left(\frac{\beta-\mu_{t+1}}{\sigma}\right)} \quad \text { for } \alpha E(0.5,1]
$$

The last two equations imply that knowing $\beta$ means knowing $\alpha$; thereby we are able to retrieve identical forecast through symmetric loss and the truncated density, that is, the condition of reciprocity is fulfilled. Similar analysis holds for the case of general non-normality (see Christodoulakis, 2006).

\subsection{Estimations of Loss Truncation for Year-Ahead Forecasts}

Equations (9a) and (9b) can be solved numerically with respect to the truncation point $\beta$ provided that estimates of $\alpha, \mu$ and $\sigma$ exist. Recall that we provide estimates of $\alpha$ above. Next, we generate symmetric-loss optimal one-step-ahead forecasts using an MA(1) process. ${ }^{5}$ This process provides two additional inputs: the conditional mean $\mu$ and the standard deviation $\sigma$, for equations (9a) and (9b), which we then solve numerically with respect to $\beta$.

From equations (8) and (9) we see that values of $a$ less than 0.5 are associated with a truncated density from above, while values of $a$ greater than 0.5 are associated with a truncated density from below. Using the year-ahead forecasts $\mu_{t+1}$ generated from an MA(1) process for each variable and the associated standard error $\sigma$, we solve equations (8a) (if $\alpha<0.5$ ) and (8b) ${ }^{6}$ (if $\alpha>0.5$ ) in each year for all variables of our dataset, with respect to $\beta$. The average values of this exercise are reported in Table VI and constitute a (nonlinear) mapping of asymmetric preferences as presented in Tables $\mathrm{I}-\mathrm{V}$ onto forecasts with underlying symmetric preferences but asymmetric densities. The correspondence between the two representations is 'one-to-one', ${ }^{7}$ so Table VI does not differ qualitatively in terms of results, but indeed it does differ in terms of interpretation. For example, inflation year-ahead forecasts for Germany revealed a statistically significant 'prudent' estimate for ' $\alpha$ ' in Table I equal to 0.68 , thus exhibiting higher costs for under-prediction as compared to over-prediction. The analogue in Table VI is that although loss preference is assumed to remain symmetric, the forecaster appears to behave as if the density were truncated from below at the point 2.25 , showing that the Commission forecasts set inflation as if having zero probability, on average, to fall bellow 2.25 over the sample period. Similar interpretation holds for 'imprudent' cases, e.g. Spain, for which a truncation point of $1.45 \%$ from above signifies that the Commission

\footnotetext{
${ }^{5}$ We have estimated various specifications from the ARMA class of processes for all the variables. From these processes we selected an MA(1) as the best proxy. This process forecasts non-trivially one-step-ahead only; thereby it is sufficient for our purposes as in this section we focus on one-year-ahead forecasts. Further details are available from the authors upon request.

${ }^{6}$ For each variable $(i)$ where $i=1,2, \ldots, 5$ and with sample size $T_{i}$ we solve numerically $T_{i}$ equations.

${ }^{7}$ For a proof of the conditions applied see Christodoulakis (2006).
} 
Table VI. Mean of truncation points over the sample period

\begin{tabular}{|c|c|c|c|c|c|}
\hline & Inflation & Unt. & Gov. Bal. & Investment & $\mathrm{CA}$ \\
\hline Bel. & $1.90 \mathrm{~b}$ & $4.12 b$ & $-7.03 b$ & $-3.53 b$ & $-0.65 b$ \\
\hline Den. & $6.40 \mathrm{a}$ & $8.01 \mathrm{a}$ & $-2.36 b$ & $11.96 \mathrm{a}$ & $3.00 \mathrm{a}$ \\
\hline Ger. & $2.25 \mathrm{~b}$ & $2.07 \mathrm{~b}$ & $-4.45 b$ & $-1.18 b$ & $2.76 \mathrm{a}$ \\
\hline Gr. & $9.43 \mathrm{a}$ & $6.77 \mathrm{a}$ & $-6.49 b$ & $-0.49 b$ & $-4.48 b$ \\
\hline Sp. & $1.45 \mathrm{a}$ & $0.44 \mathrm{~b}$ & $-2.91 b$ & $-0.10 b$ & $0.85 \mathrm{a}$ \\
\hline Fr. & $7.96 \mathrm{a}$ & $10.92 \mathrm{a}$ & $0.01 \mathrm{a}$ & $-1.69 b$ & $-0.72 b$ \\
\hline Irl. & $4.37 b$ & $10.20 \mathrm{~b}$ & $-1.64 \mathrm{a}$ & n.a. & $4.30 \mathrm{a}$ \\
\hline It. & $8.13 \mathrm{a}$ & $12.60 \mathrm{a}$ & $-8.60 b$ & $-2.46 b$ & $-1.03 b$ \\
\hline Lux. & $1.15 \mathrm{~b}$ & $1.81 \mathrm{a}$ & $1.71 \mathrm{a}$ & $16.47 \mathrm{a}$ & $25.35 \mathrm{a}$ \\
\hline Neth. & $1.10 \mathrm{~b}$ & $3.54 \mathrm{~b}$ & $-0.81 \mathrm{a}$ & $1.14 \mathrm{a}$ & $0.94 b$ \\
\hline Por. & $3.61 \mathrm{a}$ & $0.43 b$ & $-1.89 \mathrm{a}$ & $2.41 \mathrm{~b}$ & $-2.85 b$ \\
\hline UK & $2.31 \mathrm{~b}$ & $2.83 b$ & $-4.19 b$ & $-2.12 b$ & $0.42 \mathrm{a}$ \\
\hline $\mathrm{EU}$ & $6.89 \mathrm{a}$ & $10.46 \mathrm{a}$ & $-4.31 b$ & $-1.82 b$ & $0.12 \mathrm{a}$ \\
\hline
\end{tabular}

Note: 'a' indicates truncation point from above; 'b' indicates truncation point from below. Gov. Bal., CA and Unt. denote government balance, current Account and unemployment, respectively.

behaves optimistically, as if inflation has zero possibility to exceed this value over the sample period.

Turning our attention to unemployment, consider the statistically significant prudent value of $\alpha=0.66$ for the UK in Table II, which reflects a mean truncation point of 2.83 from below in Table VI. This implies that the Commission behaves on average over the sample period as if unemployment has zero probability of falling below $2.83 \%$. Instead, for Luxemburg the Commission exerts optimistic preferences, as if unemployment is restricted to have zero probability of exceeding $1.81 \%$ on average over the sample period.

For the case of government balance, consider the notable case of Greece for which in Table III we observe clear optimistic preferences, given by the statistically significant $\alpha=0.71$, which reflects a mean truncation point of -6.49 from below in Table VI. The latter signifies that the Commission forecast exhibits on average over the sample period preferences that attach for government balance zero probability to deteriorate further than -6.49 . Instead, for the case of Portugal, the pessimistic view of $\alpha=0.25$ in Table III translates to the mean truncation point of -1.89 from above in Table VI, which indicates that the forecaster behaves on average as if government balance has zero chance of exceeding -1.89 .

Investment also uncovers a diversity of preferences. In Table IV we see that for the Netherlands the forecaster exhibits highly pessimistic preferences with $a=0.09$, which translates to a mean truncation point of 1.14 from above over the sample period. The latter is interpreted that the forecaster behaves on average as if investment has zero chance of exceeding $1.14 \%$. Instead, for countries such as Germany, Greece, Spain, Portugal and the UK, the forecaster behaves optimistically with estimated alphas beyond 0.62 , which translates to mean truncation points from below which range from -2.12 for the UK to 2.41 for Portugal.

Finally, our results for current account also confirm the mixed picture over prudence. Consider the case of UK for which the estimated $a=0.33$ in Table $\mathrm{V}$ uncovers prudent preferences that correspond to a mean truncation point of 0.42 from above in Table VI. That is, the Commission predicts the UK current account on average over the sample period as if the variable has zero chance of exceeding 0.42 . Contrary to this example, consider the case of France for which the 
estimated alpha is 0.64 , thus uncovering an optimistic picture for the Commission preferences over this variable. The corresponding mean truncation value in Table VI is -0.72 from below, meaning that the commission behaves on average optimistically over the sample period as if current account has zero chance of falling bellow -0.72 .

Our results in this section complement our analysis in Section III by providing an alternative view to the asymmetries in the forecaster's preferences. It is emphasized that forecasts that are consistent with asymmetric loss preferences under normality may be equivalent to forecasts under symmetric loss and (subjective) non-normality.

\section{SIMULATION RESULTS}

The results in Section 3 show explicitly that rationally biased forecasts should be attributed to the presence of asymmetric preferences in the underlying loss function of the EU Commission. However, in light of the analysis of Section 4, an issue which is worth investigating concerns whether our empirical method can still distinguish the shape of the loss function in the presence of skewness.

The presence of instruments in the Elliott et al. (2005) method imposes a number of overidentifying assumptions, so that the estimated alpha coefficient should be the same for each of the instruments, and the $J$-statistic provides a testing procedure for this. Thus, we must assess the performance of the $J$-test under skewness for each set of instruments. ${ }^{8}$ To address this issue, we design simulation experiments with the same format as those of Elliott et al. (2005), with the difference being the skew-normal error term of the data-generating process. By doing so, we measure the size of the test for the $J$-statistic: (i) for various magnitudes of estimation and forecast samples; (ii) for various values of the true alpha coefficient; and (iii) for severe positive and negative skewness in the underlying forecast error distribution. Our random data samples were generated by $Y_{t+1}=\theta^{\prime} W_{t}+E_{t}$, where $W_{t} \equiv\left(1, W_{1, t}, W_{2, t}\right)^{\prime}$ and $W_{1, t} \sim$ $N(1,1), W_{1, t} \sim N(-1,1), \theta=[1,0.5,0.5]$ as in Elliott et al. (2005). Our simulation differs in that $E_{t} \sim \mathrm{SN}(0,0.5, \lambda)$, meaning that the regression error is distributed as a skew-normal ${ }^{9}$ random variable with location parameter equal to 0 , scale parameter equal to 0.5 and shape parameter $\lambda$. The number of Monte Carlo replications is set equal to 5000. In each replication we generate a sample of $N=n_{0}+n_{\mathrm{f}}$ observations, where $n_{0}$ is the initial sample for the recursive estimation of $\theta$ in the sequence of one-step-ahead forecasts and $n_{\mathrm{f}}$ is the forecasting sample, which is subsequently used for the estimation of alpha coefficient. Optimal forecasts are calculated assuming a Lin-Lin loss $(p=1$ in equation (1)) through an equation similar to (9), where we have used the inverse skew-normal distribution instead of the normal.

Our results in Table VII concern the case of significant positive skewness, with skew-normal shape parameter $\lambda$ equal to 5 . Table VII(A) contains results for two instruments, - a constant and the lagged forecast error-in which we immediately observe that the size of the test is well controlled. Table VII(B) contains results for three instruments - a constant, the lagged forecast error and the lagged realization - where we also observe that the test is close to its nominal size, though slightly undersized. We also observe that the size of the test gets closer to its nominal

\footnotetext{
${ }^{8}$ In addition, the same simulation experiment is carried out using the same set of instruments for testing the size of the $t$-test. Results are reported in Appendix Tables C.I and C.II.

${ }^{9}$ See, for example, Arnold and Lin (2004) and references therein.
} 
Table VII. Size of J-test (nominal size 5\%) Under skew-normal $\lambda=5$

\begin{tabular}{|c|c|c|c|c|c|c|}
\hline \multicolumn{7}{|c|}{ (A) Instruments: constant, lagged forecast error } \\
\hline$n_{0}$ & $n_{f}$ & 0.2 & 0.4 & 0.5 & 0.6 & 0.8 \\
\hline 50 & 50 & 0.0430 & 0.0474 & 0.0474 & 0.0570 & 0.0562 \\
\hline 50 & 100 & 0.0520 & 0.0504 & 0.0512 & 0.0514 & 0.0536 \\
\hline 100 & 50 & 0.0482 & 0.0496 & 0.0492 & 0.0540 & 0.0510 \\
\hline 100 & 100 & 0.0562 & 0.0552 & 0.0518 & 0.0476 & 0.0626 \\
\hline 100 & 200 & 0.0514 & 0.0538 & 0.0518 & 0.0502 & 0.0484 \\
\hline \multicolumn{7}{|c|}{ (B) Instruments: constant, lagged forecast error, lagged realized variable } \\
\hline$n_{0}$ & $n_{f}$ & 0.2 & 0.4 & 0.5 & 0.6 & 0.8 \\
\hline 50 & 50 & 0.0312 & 0.0442 & 0.0494 & 0.0490 & 0.0348 \\
\hline 50 & 100 & 0.0446 & 0.0518 & 0.0464 & 0.0550 & 0.0484 \\
\hline 100 & 50 & 0.0312 & 0.0474 & 0.0448 & 0.0494 & 0.0360 \\
\hline 100 & 100 & 0.0452 & 0.0450 & 0.0524 & 0.0508 & 0.0514 \\
\hline 100 & 200 & 0.0502 & 0.0520 & 0.0528 & 0.0500 & 0.0510 \\
\hline
\end{tabular}

Note: $\lambda$ denotes the shape parameter of skew-normal, $n_{0}$ is the size of initial sample for the recursive estimation of regression parameters, $n_{\mathrm{f}}$ is the sample size used to estimate $\alpha .0 .2,0.4, \ldots 0.8$ are values for the true $a$ parameter.

Table VIII. Size of J-test (nominal size 5\%) under skew-normal $\lambda=-5$

\begin{tabular}{lrccccc}
\hline \multicolumn{7}{c}{ (A) Instruments: constant, lagged forecast error } \\
\hline$n_{0}$ & \multicolumn{7}{c}{$n_{\mathrm{f}}$} & 0.2 & 0.4 & 0.5 & 0.6 & 0.8 \\
\hline 50 & 50 & 0.0126 & 0.0144 & 0.0136 & 0.0106 & 0.0080 \\
50 & 100 & 0.0182 & 0.0156 & 0.0124 & 0.0164 & 0.0136 \\
100 & 50 & 0.0120 & 0.0162 & 0.0126 & 0.0106 & 0.0074 \\
100 & 100 & 0.0164 & 0.0156 & 0.0144 & 0.0100 & 0.0128 \\
100 & 200 & 0.0134 & 0.0142 & 0.0144 & 0.0132 & 0.0158
\end{tabular}

(B) Instruments: constant, lagged forecast error, lagged realized variable

\begin{tabular}{lrccccc}
\hline$n_{0}$ & $n_{f}$ & 0.2 & 0.4 & 0.5 & 0.6 & 0.8 \\
\hline 50 & 50 & 0.0310 & 0.0496 & 0.0474 & 0.0458 & 0.0338 \\
50 & 100 & 0.0508 & 0.0548 & 0.0456 & 0.0490 & 0.0432 \\
100 & 50 & 0.0370 & 0.0562 & 0.0540 & 0.0446 & 0.0284 \\
100 & 100 & 0.0446 & 0.0528 & 0.0492 & 0.0514 & 0.0430 \\
100 & 200 & 0.0536 & 0.0498 & 0.0524 & 0.0520 & 0.0526 \\
\hline
\end{tabular}

Note: $\lambda$ denotes the shape parameter of skew-normal, $n_{0}$ is the size of initial sample for the recursive estimation of regression parameters, $n_{\mathrm{f}}$ is the sample size used to estimate $\alpha .0 .2,0.4, \ldots 0.8$ are values for the true $a$ parameter.

value for true alpha coefficients closer to 0.5 as well as for larger sample sizes, results which also hold under normality.

Table VIII concerns the case of significant negative skewness, with skew-normal shape parameter $\lambda$ equal to -5 . Overall, our results show that the size of the test is well controlled. For two instruments, in Table VIII(A) we show the test to be relatively undersized, while the results 
for three instruments Table VIII(B) show the $J$-test to be very close to its nominal size. Again, we observe the pattern that the size of the test gets closer to its nominal value for true alpha coefficients closer to 0.5 and for larger sample sizes, as expected. Overall, we observe that the $J$-test is very robust in the presence of significant positive or negative skewness. Of particular interest is the behaviour of the $J$-statistic for symmetric preferences (0.5), under which the presence of skewness according to our analysis of Section 4 would yield optimal forecasts that are away from the conditional expectation. The size of the test is shown to be well controlled.

Our findings from the simulation exercise show that in the presence of skewness in the underlying forecast error distribution the performance of the $J$-test is not affected. As a result, the empirical evidence on the existence of asymmetric preferences in the underlying loss function of the EU Commission is justified.

\section{CONCLUSIONS}

Given that forecasts on inflation, current account, government balances, unemployment and investment constitute the major macroeconomic aggregates underlying the process of forming the annual government budget, they are most relevant for short-term economic policy analysis, where the objective is especially to take timely corrective action if appropriate. Thus, forecast errors due to asymmetries in the underling loss function of the guardian of the Stability and Growth Pact could impair the quality of the Commission assessment over the applied and projected national economic policies. An optimistic forecast for government balance could delay fiscal consolidation; by the same token optimistic projections for unemployment could reflect upon reforms in labour markets, i.e. through persuasion of active labour market policies, as less pressing.

The Commission forecasts are often accused by the press of being too optimistic. In this paper we examine the structure of loss preferences of Commission forecasts for inflation, investment, government deficit, current account and unemployment in the context of asymmetric flexible loss functions. First, we follow a newly established method proposed by Elliott et al. (2005) and present estimates for the loss function asymmetry parameter as well as results from a joint test of forecast rationality and a flexible loss function. Our empirical evidence is robust across loss functions and instrumental variables and suggests clearly that the forecaster's loss preferences tend to vary across different MSs of EU and different variables. The estimation concerns year-ahead and current-year forecasts. Our findings show that Commission forecasts display for some MSs optimism for the year-ahead forecasts, whereas for the current year the estimated loss preferences lean towards pessimism, which could be interpreted as a prudent attitude. Second, we complement our results with an analysis, which uncovers a correspondence between the estimated preference asymmetries and equivalent forecasts generated under a symmetric loss function and non-normality, thus providing an alternative interpretation for preference asymmetries. In addition, a simulation exercise was carried out to show that in the presence of skewness in the underlying forecast error distribution the size performance of the $J$-test is not affected. As a result, the empirical evidence of the existence of asymmetric preferences in the underlying loss function of the EU Commission is justified. 


\section{APPENDIX}

Table A.I. Inflation under asymmetric quadratic loss function

\begin{tabular}{|c|c|c|c|c|c|c|c|c|c|c|c|c|}
\hline \multicolumn{7}{|c|}{ Current year } & \multicolumn{6}{|c|}{ Year ahead } \\
\hline & $\hat{\alpha}$ & SE & $J_{\hat{\alpha}}$ & $J_{\alpha=0.2}$ & $J_{\alpha=0.5}$ & $J_{\alpha=0.8}$ & $\hat{\alpha}$ & SE & $J_{\hat{\alpha}}$ & $J_{\alpha=0.2}$ & $J_{\alpha=0.5}$ & $J_{\alpha=0.8}$ \\
\hline Bel. & 0.5 & 0.1 & 0.4 & 6.4 & 0.41 & 6.14 & 0.6 & 0.12 & 2.12 & 9.84 & 3.33 & 3.32 \\
\hline Den. & 0.36 & 0.1 & 0.07 & 2.59 & 1.57 & 8.37 & 0.3 & 0.1 & 4 & 4.58 & 4.08 & 8.79 \\
\hline Ger. & 0.66 & 0.1 & 0.8 & 10.5 & 3.13 & 2.55 & 0.69 & 0.1 & 5.83 & 11.6 & 9.32 & 5.32 \\
\hline Gr. & 0.42 & 0.13 & 1.25 & 3.57 & 1.64 & 4.06 & 0.01 & 0.02 & 4.92 & 4.01 & 4.18 & 6.49 \\
\hline Sp. & 0.11 & 0.06 & 1.67 & 2.81 & 5.57 & 6.63 & 0.02 & 0.04 & 3.4 & 3.31 & 4.57 & 6.8 \\
\hline Fr. & 0.57 & 0.11 & 1.21 & 7.62 & 1.55 & 4.62 & 0.34 & 0.1 & 0.45 & 2.61 & 2.37 & 7.83 \\
\hline Ire. & 0.52 & 0.11 & 1.47 & 7.38 & 1.54 & 5.06 & 0.55 & 0.12 & 2.43 & 9.73 & 2.95 & 3.91 \\
\hline Ital & 0.16 & 0.06 & 3.37 & 3.93 & 10.1 & 12.6 & 0.07 & 0.04 & 1.46 & 3.57 & 8.2 & 9.73 \\
\hline Lux. & 0.53 & 0.1 & 1.77 & 8.39 & 1.82 & 6.07 & 0.11 & 0.11 & 0.03 & 0.45 & 2.83 & 3.73 \\
\hline Neth. & 0.45 & 0.1 & 0.66 & 5.95 & 0.91 & 6.82 & 0.6 & 0.11 & 3.29 & 8.08 & 3.55 & 5.48 \\
\hline Port. & 0 & 0.02 & 2.99 & 6.4 & 7.1 & 8.92 & 0.01 & 0.01 & 4.62 & 2.06 & 4.12 & 5.64 \\
\hline UK & 0.69 & 0.11 & 0.03 & 8.82 & 2.41 & 0.99 & 0.58 & 0.12 & 2.21 & 8.06 & 2.84 & 3.82 \\
\hline EU & 0.47 & 0.11 & 3.01 & 5.75 & 3.22 & 6.92 & 0.25 & 0.09 & 3.61 & 3.55 & 5.71 & 7.37 \\
\hline
\end{tabular}

Note: Estimates are based on $D=3$ instruments. $J$-statistics are distributed as $\chi^{2}(D-1)$ or $J_{\hat{\alpha}}$ and $\chi^{2}(D)$ for the remaining $J$.

Table A.II. Government balance under asymmetric quadratic loss function

\begin{tabular}{|c|c|c|c|c|c|c|c|c|c|c|c|c|}
\hline \multicolumn{7}{|c|}{ Current year } & \multicolumn{6}{|c|}{ Year ahead } \\
\hline & $\hat{\alpha}$ & SE & $J_{\hat{\alpha}}$ & $J_{\alpha=0.2}$ & $J_{\alpha=0.5}$ & $J_{\alpha=0.8}$ & $\hat{\alpha}$ & $\mathrm{SE}$ & $J_{\hat{\alpha}}$ & $J_{\alpha=0.2}$ & $J_{\alpha=0.5}$ & $J_{\alpha=0.8}$ \\
\hline Bel. & 0.00 & 0.00 & 7.31 & 5.72 & 3.91 & 4.37 & 0.76 & 0.08 & 0.37 & 10.03 & 4.98 & 0.62 \\
\hline Den. & 0.01 & 0.11 & 6.97 & 8.41 & 4.85 & 4.37 & 0.71 & 0.10 & 5.43 & 10.90 & 8.71 & 4.87 \\
\hline Ger. & 0.04 & 0.03 & 4.38 & 10.13 & 18.73 & 21.29 & 0.59 & 0.10 & 3.22 & 7.03 & 3.54 & 5.22 \\
\hline Gr. & 0.00 & 0.00 & 4.49 & 9.15 & 9.06 & 9.86 & 0.91 & 0.07 & 3.84 & 9.51 & 7.67 & 5.52 \\
\hline Sp.n & 0.68 & 0.13 & 1.79 & 3.28 & 2.04 & 2.16 & 0.83 & 0.09 & 0.68 & 5.20 & 3.36 & 0.73 \\
\hline Fr. & 0.58 & 0.12 & 0.60 & 4.63 & 0.80 & 3.89 & 0.76 & 0.09 & 2.25 & 6.58 & 3.08 & 2.64 \\
\hline Ire. & 0.07 & 0.04 & 1.78 & 2.94 & 4.06 & 5.72 & 0.43 & 0.11 & 2.08 & 4.51 & 2.17 & 8.54 \\
\hline Ital & 0.62 & 0.17 & 0.25 & 3.03 & 0.49 & 1.22 & 0.43 & 0.14 & 1.34 & 2.86 & 1.38 & 4.00 \\
\hline Lux. & 0.12 & 0.07 & 2.18 & 3.03 & 7.75 & 13.26 & 0.10 & 0.05 & 2.69 & 3.81 & 9.77 & 15.67 \\
\hline Neth. & 0.37 & 0.10 & 0.26 & 2.45 & 1.75 & 11.32 & 0.50 & 0.10 & 2.77 & 6.11 & 2.79 & 8.19 \\
\hline Port. & 0.23 & 0.13 & 1.31 & 1.30 & 2.80 & 6.75 & 0.23 & 0.13 & 3.28 & 3.26 & 3.52 & 3.52 \\
\hline UK & 0.57 & 0.11 & 1.08 & 5.61 & 1.45 & 4.14 & 0.62 & 0.11 & 2.08 & 9.13 & 2.64 & 3.85 \\
\hline EU & 0.52 & 0.12 & 1.52 & 4.51 & 1.60 & 5.68 & 0.66 & 0.10 & 1.41 & 8.66 & 3.00 & 2.81 \\
\hline
\end{tabular}

Note: Estimates are based on $D=3$ instruments. $J$-statistics are distributed as $\chi^{2}(D-1)$ or $J_{\hat{\alpha}}$ and $\chi^{2}(D)$ for the remaining $J$.

Table A.III. Unemployment under asymmetric quadratic loss function

\begin{tabular}{|c|c|c|c|c|c|c|c|c|c|c|c|c|}
\hline \multicolumn{7}{|c|}{ Current year } & \multicolumn{6}{|c|}{ Year ahead } \\
\hline & $\hat{\alpha}$ & SE & $J_{\hat{\alpha}}$ & $J_{\alpha=0.2}$ & $J_{\alpha=0.5}$ & $J_{\alpha=0.8}$ & $\hat{\alpha}$ & SE & $J_{\hat{\alpha}}$ & $J_{\alpha=0.2}$ & $J_{\alpha=0.5}$ & $J_{\alpha=0.8}$ \\
\hline Bel. & 0.60 & 0.10 & 7.18 & 9.10 & 7.94 & 7.10 & 0.92 & 0.06 & 8.97 & 8.16 & 9.14 & 10.52 \\
\hline Den. & 0.25 & 0.11 & 4.73 & 4.42 & 5.37 & 4.67 & 0.64 & 0.10 & 4.12 & 8.48 & 6.04 & 4.58 \\
\hline
\end{tabular}


Table A.III. (Continued)

\begin{tabular}{|c|c|c|c|c|c|c|c|c|c|c|c|c|}
\hline \multicolumn{7}{|c|}{ Current year } & \multicolumn{6}{|c|}{ Year ahead } \\
\hline & $\hat{\alpha}$ & SE & $J_{\hat{\alpha}}$ & $J_{\alpha=0.2}$ & $J_{\alpha=0.5}$ & $J_{\alpha=0.8}$ & $\hat{\alpha}$ & SE & $J_{\hat{\alpha}}$ & $J_{\alpha=0.2}$ & $J_{\alpha=0.5}$ & $J_{\alpha=0.8}$ \\
\hline Ger. & 0.50 & 0.12 & 6.16 & 7.04 & 6.14 & 5.44 & 0.59 & 0.11 & 6.29 & 6.23 & 5.98 & 6.52 \\
\hline Gr. & 0.33 & 0.13 & 5.05 & 5.21 & 4.33 & 4.56 & 0.34 & 0.12 & 3.12 & 3.41 & 2.99 & 5.69 \\
\hline Sp.n & 0.86 & 0.10 & 1.06 & 7.26 & 3.75 & 1.21 & 0.79 & 0.10 & 3.63 & 5.77 & 6.16 & 3.59 \\
\hline Fr. & 0.51 & 0.11 & 2.55 & 6.24 & 2.52 & 6.44 & 0.50 & 0.11 & 2.30 & 5.68 & 2.30 & 5.71 \\
\hline Ire. & 0.79 & 0.09 & 0.70 & 11.50 & 5.75 & 0.72 & 0.97 & 0.04 & 7.20 & 9.93 & 6.08 & 7.31 \\
\hline Ital & 0.47 & 0.13 & 2.15 & 4.07 & 2.20 & 4.18 & 0.31 & 0.10 & 3.93 & 3.85 & 5.13 & 6.19 \\
\hline Lux. & 0.52 & 0.11 & 2.17 & 6.13 & 2.08 & 5.57 & 0.36 & 0.12 & 3.73 & 3.82 & 4.85 & 8.98 \\
\hline Neth. & 1.04 & 0.10 & 6.09 & 7.39 & 3.46 & 6.03 & 0.68 & 0.11 & 4.14 & 8.00 & 3.71 & 4.59 \\
\hline Port. & 1.00 & 0.02 & 3.93 & 7.43 & 3.78 & 3.43 & 0.96 & 0.05 & 5.32 & 5.78 & 4.60 & 6.54 \\
\hline UK & 0.80 & 0.08 & 3.34 & 13.50 & 6.66 & 3.33 & 0.88 & 0.09 & 3.75 & 7.91 & 4.83 & 4.07 \\
\hline EU & 0.36 & 0.10 & 5.30 & 5.70 & 5.03 & 6.33 & 0.55 & 0.12 & 7.26 & 5.53 & 7.14 & 7.12 \\
\hline
\end{tabular}

Note: Estimates are based on $D=3$ instruments. $J$-statistics are distributed as $\chi^{2}(D-1)$ or $J_{\hat{\alpha}}$ and $\chi^{2}(D)$ for the remaining $J$.

Table A.IV. Investment under asymmetric quadratic loss function

\begin{tabular}{|c|c|c|c|c|c|c|c|c|c|c|c|c|}
\hline \multicolumn{7}{|c|}{ Current year } & \multicolumn{6}{|c|}{ Year ahead } \\
\hline & $\hat{\alpha}$ & SE & $J_{\hat{\alpha}}$ & $J_{\alpha=0.2}$ & $J_{\alpha=0.5}$ & $J_{\alpha=0.8}$ & $\hat{\alpha}$ & SE & $J_{\hat{\alpha}}$ & $J_{\alpha=0.2}$ & $J_{\alpha=0.5}$ & $J_{\alpha=0.8}$ \\
\hline Bel. & 0.62 & 0.11 & 1.88 & 9.65 & 3.15 & 3.07 & 0.61 & 0.11 & 2.54 & 8.51 & 3.75 & 3.51 \\
\hline Den. & 0.15 & 0.07 & 1.60 & 1.75 & 5.43 & 9.82 & 0.20 & 0.07 & 0.65 & 0.66 & 5.03 & 9.25 \\
\hline Ger. & 0.77 & 0.08 & 3.54 & 10.62 & 5.53 & 4.14 & 0.71 & 0.09 & 2.47 & 11.42 & 4.29 & 4.05 \\
\hline Gr. & 0.62 & 0.13 & 0.28 & 6.54 & 1.04 & 2.04 & 0.63 & 0.13 & 0.46 & 7.60 & 1.43 & 1.98 \\
\hline Sp.n & 0.20 & 0.11 & 6.26 & 6.22 & 7.01 & 5.20 & 0.89 & 0.08 & 4.13 & 6.29 & 5.62 & 5.07 \\
\hline Fr. & 0.62 & 0.10 & 0.20 & 9.30 & 1.50 & 3.17 & 0.68 & 0.10 & 3.45 & 10.54 & 3.69 & 4.81 \\
\hline Ire. & 0.84 & 0.07 & 6.28 & 7.08 & 7.47 & 6.69 & 0.56 & 0.10 & 0.89 & 7.27 & 1.08 & 5.81 \\
\hline Ital & 0.46 & 0.13 & 0.75 & 5.41 & 0.79 & 3.45 & 0.66 & 0.10 & 0.87 & 9.72 & 2.22 & 2.63 \\
\hline Lux. & 0.38 & 0.11 & 1.98 & 4.04 & 2.44 & 7.51 & 0.32 & 0.10 & 0.86 & 2.25 & 2.50 & 7.81 \\
\hline Neth. & 0.32 & 0.10 & 1.64 & 2.66 & 2.90 & 7.76 & 0.02 & 0.02 & 2.84 & 8.35 & 10.32 & 14.72 \\
\hline Port. & 0.56 & 0.14 & 0.89 & 4.23 & 0.93 & 2.68 & 0.76 & 0.13 & 2.69 & 4.57 & 3.34 & 2.58 \\
\hline UK & 0.71 & 0.09 & 2.91 & 8.64 & 4.51 & 3.27 & 0.58 & 0.12 & 4.33 & 7.38 & 4.75 & 4.56 \\
\hline EU & 0.92 & 0.06 & 4.60 & 11.34 & 5.07 & 2.81 & 0.77 & 0.09 & 2.74 & 10.09 & 4.27 & 3.01 \\
\hline
\end{tabular}

Note: Estimates are based on $D=3$ instruments. $J$-statistics are distributed as $\chi^{2}(D-1)$ or $J_{\hat{\alpha}}$ and $\chi^{2}(D)$ for the remaining $J$.

Table A.V. Current account under asymmetric quadratic loss function

\begin{tabular}{|c|c|c|c|c|c|c|c|c|c|c|c|c|}
\hline \multicolumn{7}{|c|}{ Current year } & \multicolumn{6}{|c|}{ Year ahead } \\
\hline & $\hat{\alpha}$ & $\mathrm{SE}$ & $J_{\hat{\alpha}}$ & $J_{\alpha=0.2}$ & $J_{\alpha=0.5}$ & $J_{\alpha=0.8}$ & $\hat{\alpha}$ & SE & $J_{\hat{\alpha}}$ & $J_{\alpha=0.2}$ & $J_{\alpha=0.5}$ & $J_{\alpha=0.8}$ \\
\hline Bel. & 0.54 & 0.11 & 2.99 & 6.71 & 3.25 & 5.95 & 0.59 & 0.11 & 7.42 & 11.32 & 8.68 & 6.29 \\
\hline Den. & 0.54 & 0.11 & 0.43 & 6.95 & 0.51 & 4.25 & 0.57 & 0.11 & 0.11 & 6.71 & 0.47 & 4.65 \\
\hline Ger. & 0.29 & 0.10 & 0.50 & 1.30 & 3.13 & 9.68 & 0.41 & 0.11 & 0.13 & 3.25 & 0.79 & 7.47 \\
\hline Gr. & 0.91 & 0.06 & 1.41 & 8.86 & 5.68 & 2.38 & 0.97 & 0.03 & 4.68 & 6.83 & 2.92 & 3.12 \\
\hline Sp.n & 0.97 & 0.09 & 3.30 & 6.80 & 5.04 & 5.05 & 0.95 & 0.06 & 6.73 & 3.71 & 5.72 & 7.53 \\
\hline Fr. & 0.52 & 0.11 & 1.05 & 6.80 & 1.06 & 5.91 & 0.45 & 0.10 & 1.42 & 7.18 & 1.68 & 7.17 \\
\hline
\end{tabular}


Table A.V. (Continued)

\begin{tabular}{|c|c|c|c|c|c|c|c|c|c|c|c|c|}
\hline \multicolumn{7}{|c|}{ Current year } & \multicolumn{6}{|c|}{ Year ahead } \\
\hline & $\hat{\alpha}$ & SE & $J_{\hat{\alpha}}$ & $J_{\alpha=0.2}$ & $J_{\alpha=0.5}$ & $J_{\alpha=0.8}$ & $\hat{\alpha}$ & $\mathrm{SE}$ & $J_{\hat{\alpha}}$ & $J_{\alpha=0.2}$ & $J_{\alpha=0.5}$ & $J_{\alpha=0.8}$ \\
\hline Ire. & 0.39 & 0.12 & 3.59 & 4.38 & 3.41 & 6.76 & 0.50 & 0.12 & 0.91 & 5.57 & 0.91 & 4.80 \\
\hline Ital & 0.73 & 0.10 & 2.81 & 10.29 & 5.21 & 2.84 & 0.83 & 0.08 & 3.35 & 9.59 & 5.96 & 3.50 \\
\hline Lux. & 0.45 & 0.14 & 4.81 & 6.58 & 4.75 & 5.04 & 0.47 & 0.14 & 0.39 & 3.42 & 0.43 & 4.12 \\
\hline Neth. & 0.59 & 0.10 & 3.40 & 6.57 & 3.41 & 5.77 & 0.82 & 0.07 & 8.22 & 9.23 & 9.58 & 8.53 \\
\hline Port. & 0.62 & 0.14 & 0.69 & 3.95 & 1.09 & 2.49 & 0.71 & 0.13 & 0.26 & 6.07 & 2.23 & 0.84 \\
\hline UK & 0.42 & 0.11 & 2.03 & 4.93 & 1.97 & 6.80 & 0.30 & 0.11 & 1.20 & 1.82 & 3.70 & 7.88 \\
\hline EU & 0.51 & 0.11 & 3.20 & 6.38 & 3.27 & 5.48 & 0.34 & 0.11 & 8.04 & 6.75 & 10.35 & 10.12 \\
\hline
\end{tabular}

Note: Estimates are based on $D=3$ instruments. $J$-statistics are distributed as $\chi^{2}(D-1)$ or $J_{\hat{\alpha}}$ and $\chi^{2}(D)$ for the remaining $J$.

Table B.I. Inflation under asymmetric linear loss function

\begin{tabular}{|c|c|c|c|c|c|c|c|c|c|c|c|c|}
\hline \multicolumn{7}{|c|}{ Current year } & \multicolumn{6}{|c|}{ Year ahead } \\
\hline & \multicolumn{2}{|c|}{$D=1$} & \multicolumn{2}{|c|}{$D=2(\mathrm{fe})$} & \multicolumn{2}{|c|}{$D=2(\operatorname{tr})$} & \multicolumn{2}{|c|}{$D=1$} & \multicolumn{2}{|c|}{$D=2(\mathrm{fe})$} & \multicolumn{2}{|c|}{$D=2(\operatorname{tr})$} \\
\hline & $\hat{\alpha}$ & SE & $\hat{\alpha}$ & SE & $\hat{\alpha}$ & SE & $\hat{\alpha}$ & SE & $\hat{\alpha}$ & SE & $\hat{\alpha}$ & SE \\
\hline Bel. & 0.43 & 0.08 & 0.43 & 0.08 & 0.42 & 0.08 & 0.56 & 0.09 & 0.59 & 0.08 & 0.56 & 0.09 \\
\hline Den. & 0.42 & 0.09 & 0.42 & 0.09 & 0.42 & 0.09 & 0.43 & 0.09 & 0.43 & 0.09 & 0.43 & 0.09 \\
\hline Ger. & 0.49 & 0.08 & 0.49 & 0.08 & 0.49 & 0.08 & 0.62 & 0.08 & 0.66 & 0.08 & 0.63 & 0.08 \\
\hline Gr. & 0.48 & 0.10 & 0.48 & 0.10 & 0.47 & 0.10 & 0.36 & 0.10 & 0.36 & 0.10 & 0.36 & 0.10 \\
\hline $\mathrm{Sp}$. & 0.33 & 0.11 & 0.23 & 0.10 & 0.30 & 0.11 & 0.24 & 0.10 & 0.06 & 0.06 & 0.23 & 0.10 \\
\hline Fr. & 0.43 & 0.08 & 0.43 & 0.08 & 0.43 & 0.08 & 0.44 & 0.09 & 0.44 & 0.09 & 0.43 & 0.08 \\
\hline Ire. & 0.55 & 0.09 & 0.56 & 0.09 & 0.55 & 0.09 & 0.63 & 0.09 & 0.69 & 0.08 & 0.65 & 0.09 \\
\hline Ital & 0.31 & 0.08 & 0.30 & 0.08 & 0.28 & 0.08 & 0.21 & 0.07 & 0.21 & 0.07 & 0.21 & 0.07 \\
\hline Lux. & 0.49 & 0.08 & 0.48 & 0.08 & 0.49 & 0.08 & 0.53 & 0.03 & 0.53 & 0.04 & 0.53 & 0.04 \\
\hline Neth. & 0.49 & 0.08 & 0.49 & 0.08 & 0.48 & 0.08 & 0.53 & 0.09 & 0.54 & 0.09 & 0.53 & 0.09 \\
\hline Port. & 0.17 & 0.09 & 0.02 & 0.04 & 0.09 & 0.07 & 0.35 & 0.12 & 0.34 & 0.11 & 0.35 & 0.12 \\
\hline UK & 0.58 & 0.09 & 0.59 & 0.09 & 0.58 & 0.09 & 0.60 & 0.09 & 0.62 & 0.09 & 0.60 & 0.09 \\
\hline EU & 0.49 & 0.08 & 0.48 & 0.08 & 0.48 & 0.08 & 0.41 & 0.08 & 0.36 & 0.08 & 0.41 & 0.08 \\
\hline
\end{tabular}

Note: Estimates are based on $D=1$, where the instrument is the constant, $D=2$ (fe), where the instruments are the constant and the lagged forecast error, and $D=3(\operatorname{tr})$, where the instruments are the constant and the lagged realization.

Table B.II. Government Balance under asymmetric linear loss function

\begin{tabular}{|c|c|c|c|c|c|c|c|c|c|c|c|c|}
\hline \multicolumn{7}{|c|}{ Current year } & \multicolumn{6}{|c|}{ Year ahead } \\
\hline & \multicolumn{2}{|c|}{$D=1$} & \multicolumn{2}{|c|}{$D=2(\mathrm{fe})$} & \multicolumn{2}{|c|}{$D=2(\operatorname{tr})$} & \multicolumn{2}{|c|}{$D=1$} & \multicolumn{2}{|c|}{$D=2(\mathrm{fe})$} & \multicolumn{2}{|c|}{$D=2(\operatorname{tr})$} \\
\hline & $\hat{\alpha}$ & SE & $\hat{\alpha}$ & SE & $\hat{\alpha}$ & SE & $\hat{\alpha}$ & SE & $\hat{\alpha}$ & SE & $\hat{\alpha}$ & SE \\
\hline Bel. & 0.33 & 0.08 & 0.01 & 0.02 & 0.27 & 0.08 & 0.55 & 0.09 & 0.55 & 0.09 & 0.55 & 0.09 \\
\hline Den. & 0.59 & 0.09 & 0.59 & 0.09 & 0.63 & 0.09 & 0.56 & 0.10 & 0.56 & 0.10 & 0.58 & 0.10 \\
\hline Ger. & 0.17 & 0.06 & 0.02 & 0.02 & 0.08 & 0.05 & 0.47 & 0.09 & 0.47 & 0.09 & 0.46 & 0.09 \\
\hline Gr. & 0.23 & 0.09 & 0.00 & 0.01 & 0.02 & 0.03 & 0.59 & 0.10 & 0.61 & 0.10 & 0.61 & 0.10 \\
\hline Sp.n & 0.44 & 0.12 & 0.44 & 0.12 & 0.44 & 0.12 & 0.47 & 0.12 & 0.47 & 0.12 & 0.47 & 0.12 \\
\hline
\end{tabular}


Table B.II. (Continued)

\begin{tabular}{|c|c|c|c|c|c|c|c|c|c|c|c|c|}
\hline \multicolumn{7}{|c|}{ Current year } & \multicolumn{6}{|c|}{ Year ahead } \\
\hline & \multicolumn{2}{|c|}{$D=1$} & \multicolumn{2}{|c|}{$D=2(\mathrm{fe})$} & \multicolumn{2}{|c|}{$D=2(\operatorname{tr})$} & \multicolumn{2}{|c|}{$D=1$} & \multicolumn{2}{|c|}{$D=2(\mathrm{fe})$} & \multicolumn{2}{|c|}{$D=2(\operatorname{tr})$} \\
\hline & $\hat{\alpha}$ & SE & $\hat{\alpha}$ & SE & $\hat{\alpha}$ & SE & $\hat{\alpha}$ & SE & $\hat{\alpha}$ & SE & $\hat{\alpha}$ & SE \\
\hline Fr. & 0.46 & 0.08 & 0.46 & 0.08 & 0.45 & 0.08 & 0.41 & 0.08 & 0.40 & 0.08 & 0.41 & 0.08 \\
\hline Ire. & 0.33 & 0.09 & 0.33 & 0.09 & 0.26 & 0.08 & 0.40 & 0.09 & 0.39 & 0.09 & 0.39 & 0.09 \\
\hline Ital & 0.46 & 0.08 & 0.46 & 0.08 & 0.45 & 0.08 & 0.53 & 0.09 & 0.53 & 0.09 & 0.53 & 0.09 \\
\hline Lux. & 0.17 & 0.07 & 0.16 & 0.07 & 0.12 & 0.06 & 0.28 & 0.08 & 0.27 & 0.08 & 0.27 & 0.08 \\
\hline Neth. & 0.31 & 0.08 & 0.31 & 0.08 & 0.31 & 0.08 & 0.35 & 0.08 & 0.34 & 0.08 & 0.35 & 0.08 \\
\hline Port. & 0.22 & 0.10 & 0.21 & 0.10 & 0.19 & 0.09 & 0.35 & 0.12 & 0.26 & 0.11 & 0.35 & 0.12 \\
\hline UK & 0.45 & 0.09 & 0.45 & 0.09 & 0.45 & 0.09 & 0.53 & 0.09 & 0.54 & 0.09 & 0.53 & 0.09 \\
\hline EU & 0.43 & 0.08 & 0.43 & 0.08 & 0.42 & 0.08 & 0.59 & 0.08 & 0.59 & 0.08 & 0.59 & 0.08 \\
\hline
\end{tabular}

Note: Estimates are based on $D=1$, where the instrument is the constant, $D=2$ (fe), where the instruments are the constant and the lagged forecast error, and $D=3(\operatorname{tr})$, where the instruments are the constant and the lagged realization.

Table B.III. Unemployment under asymmetric linear loss function

\begin{tabular}{|c|c|c|c|c|c|c|c|c|c|c|c|c|}
\hline \multicolumn{7}{|c|}{ Current year } & \multicolumn{6}{|c|}{ Year ahead } \\
\hline & \multicolumn{2}{|c|}{$D=1$} & \multicolumn{2}{|c|}{$D=2(\mathrm{fe})$} & \multicolumn{2}{|c|}{$D=2(\operatorname{tr})$} & \multicolumn{2}{|c|}{$D=1$} & \multicolumn{2}{|c|}{$D=2(\mathrm{fe})$} & \multicolumn{2}{|c|}{$D=2(\operatorname{tr})$} \\
\hline & $\hat{\alpha}$ & SE & $\hat{\alpha}$ & SE & $\hat{\alpha}$ & SE & $\hat{\alpha}$ & SE & $\hat{\alpha}$ & SE & $\hat{\alpha}$ & SE \\
\hline Bel. & 0.40 & 0.08 & 0.40 & 0.08 & 0.19 & 0.07 & 0.52 & 0.09 & 0.52 & 0.09 & 0.54 & 0.09 \\
\hline Den. & 0.45 & 0.09 & 0.45 & 0.09 & 0.44 & 0.09 & 0.47 & 0.09 & 0.46 & 0.09 & 0.46 & 0.09 \\
\hline Ger. & 0.40 & 0.08 & 0.39 & 0.08 & 0.33 & 0.08 & 0.52 & 0.09 & 0.52 & 0.09 & 0.52 & 0.09 \\
\hline Gr. & 0.57 & 0.10 & 0.57 & 0.10 & 0.57 & 0.10 & 0.45 & 0.11 & 0.45 & 0.11 & 0.45 & 0.11 \\
\hline Sp.n & 0.72 & 0.11 & 0.76 & 0.10 & 0.74 & 0.10 & 0.53 & 0.12 & 0.54 & 0.12 & 0.53 & 0.12 \\
\hline Fr. & 0.41 & 0.08 & 0.41 & 0.08 & 0.39 & 0.08 & 0.45 & 0.09 & 0.45 & 0.09 & 0.45 & 0.09 \\
\hline Ire. & 0.58 & 0.09 & 0.58 & 0.09 & 0.59 & 0.09 & 0.70 & 0.08 & 0.84 & 0.07 & 0.70 & 0.08 \\
\hline Ital & 0.49 & 0.08 & 0.49 & 0.08 & 0.49 & 0.08 & 0.48 & 0.09 & 0.48 & 0.09 & 0.48 & 0.09 \\
\hline Lux. & 0.48 & 0.09 & 0.48 & 0.09 & 0.48 & 0.09 & 0.36 & 0.09 & 0.30 & 0.09 & 0.34 & 0.09 \\
\hline Neth. & 0.57 & 0.08 & 0.57 & 0.08 & 0.58 & 0.08 & 0.58 & 0.09 & 0.59 & 0.09 & 0.58 & 0.09 \\
\hline Port. & 0.72 & 0.11 & 0.76 & 0.10 & 0.76 & 0.10 & 0.65 & 0.12 & 0.77 & 0.10 & 0.65 & 0.12 \\
\hline UK & 0.68 & 0.08 & 0.69 & 0.08 & 0.68 & 0.08 & 0.60 & 0.09 & 0.66 & 0.09 & 0.60 & 0.09 \\
\hline EU & 0.46 & 0.08 & 0.46 & 0.08 & 0.43 & 0.08 & 0.48 & 0.09 & 0.48 & 0.09 & 0.48 & 0.09 \\
\hline
\end{tabular}

Note: Estimates are based on $D=1$, where the instrument is the constant, $D=2$ (fe), where the instruments are the constant and the lagged forecast error, and $D=3(\operatorname{tr})$, where the instruments are the constant and the lagged realization.

Table B.IV. Investment under asymmetric linear loss function

\begin{tabular}{|c|c|c|c|c|c|c|c|c|c|c|c|c|}
\hline \multicolumn{7}{|c|}{ Current year } & \multicolumn{6}{|c|}{ Year ahead } \\
\hline & \multicolumn{2}{|c|}{$D=1$} & \multicolumn{2}{|c|}{$D=2(\mathrm{fe})$} & \multicolumn{2}{|c|}{$D=2(\operatorname{tr})$} & \multicolumn{2}{|c|}{$D=1$} & \multicolumn{2}{|c|}{$D=2(\mathrm{fe})$} & \multicolumn{2}{|c|}{$D=2(\operatorname{tr})$} \\
\hline & $\hat{\alpha}$ & SE & $\hat{\alpha}$ & SE & $\hat{\alpha}$ & SE & $\hat{\alpha}$ & SE & $\hat{\alpha}$ & $\mathrm{SE}$ & $\hat{\alpha}$ & SE \\
\hline Bel. & 0.57 & 0.08 & 0.57 & 0.08 & 0.57 & 0.08 & 0.50 & 0.09 & 0.50 & 0.09 & 0.50 & 0.09 \\
\hline Den. & 0.29 & 0.08 & 0.25 & 0.08 & 0.28 & 0.08 & 0.43 & 0.09 & 0.42 & 0.09 & 0.43 & 0.09 \\
\hline Ger. & 0.54 & 0.08 & 0.55 & 0.08 & 0.56 & 0.08 & 0.62 & 0.08 & 0.64 & 0.08 & 0.63 & 0.08 \\
\hline Gr. & 0.61 & 0.10 & 0.61 & 0.10 & 0.61 & 0.10 & 0.64 & 0.10 & 0.64 & 0.10 & 0.64 & 0.10 \\
\hline
\end{tabular}


Table B.IV. (Continued)

\begin{tabular}{|c|c|c|c|c|c|c|c|c|c|c|c|c|}
\hline \multicolumn{7}{|c|}{ Current year } & \multicolumn{6}{|c|}{ Year ahead } \\
\hline & \multicolumn{2}{|c|}{$D=1$} & \multicolumn{2}{|c|}{$D=2(\mathrm{fe})$} & \multicolumn{2}{|c|}{$D=2(\operatorname{tr})$} & \multicolumn{2}{|c|}{$D=1$} & \multicolumn{2}{|c|}{$D=2(\mathrm{fe})$} & \multicolumn{2}{|c|}{$D=2(\operatorname{tr})$} \\
\hline & $\hat{\alpha}$ & SE & $\hat{\alpha}$ & SE & $\hat{\alpha}$ & SE & $\hat{\alpha}$ & SE & $\hat{\alpha}$ & SE & $\hat{\alpha}$ & SE \\
\hline Sp.n & 0.39 & 0.11 & 0.30 & 0.11 & 0.39 & 0.11 & 0.59 & 0.12 & 0.59 & 0.12 & 0.59 & 0.12 \\
\hline Fr. & 0.63 & 0.08 & 0.63 & 0.08 & 0.64 & 0.08 & 0.56 & 0.09 & 0.57 & 0.08 & 0.56 & 0.09 \\
\hline Ire. & 0.39 & 0.09 & 0.38 & 0.09 & 0.39 & 0.09 & 0.50 & 0.09 & 0.50 & 0.09 & 0.50 & 0.09 \\
\hline Ital & 0.60 & 0.08 & 0.60 & 0.08 & 0.60 & 0.08 & 0.59 & 0.08 & 0.59 & 0.08 & 0.59 & 0.08 \\
\hline Lux. & 0.39 & 0.09 & 0.39 & 0.09 & 0.39 & 0.09 & 0.48 & 0.10 & 0.48 & 0.10 & 0.48 & 0.10 \\
\hline Neth. & 0.40 & 0.08 & 0.40 & 0.08 & 0.40 & 0.08 & 0.21 & 0.07 & 0.20 & 0.07 & 0.20 & 0.07 \\
\hline Port. & 0.56 & 0.12 & 0.56 & 0.12 & 0.56 & 0.12 & 0.71 & 0.11 & 0.73 & 0.11 & 0.71 & 0.11 \\
\hline UK & 0.65 & 0.09 & 0.66 & 0.09 & 0.65 & 0.09 & 0.63 & 0.09 & 0.64 & 0.09 & 0.64 & 0.09 \\
\hline EU & 0.66 & 0.08 & 0.66 & 0.08 & 0.66 & 0.08 & 0.56 & 0.09 & 0.57 & 0.09 & 0.56 & 0.09 \\
\hline
\end{tabular}

Note: Estimates are based on $D=1$, where the instrument is the constant, $D=2$ (fe), where the instruments are the constant and the lagged forecast error, and $D=3(\operatorname{tr})$, where the instruments are the constant and the lagged realization.

Table B.V. Current Account under asymmetric linear loss function

\begin{tabular}{|c|c|c|c|c|c|c|c|c|c|c|c|c|}
\hline \multicolumn{7}{|c|}{ Current year } & \multicolumn{6}{|c|}{ Year ahead } \\
\hline & \multicolumn{2}{|c|}{$\mathrm{D}=1$} & \multicolumn{2}{|c|}{$\mathrm{D}=2(\mathrm{fe})$} & \multicolumn{2}{|c|}{$\mathrm{D}=2(\operatorname{tr})$} & \multicolumn{2}{|c|}{$\mathrm{D}=1$} & \multicolumn{2}{|c|}{$\mathrm{D}=2(\mathrm{fe})$} & \multicolumn{2}{|c|}{$\mathrm{D}=2(\operatorname{tr})$} \\
\hline & $\hat{\alpha}$ & SE & $\hat{\alpha}$ & SE & $\hat{\alpha}$ & SE & $\hat{\alpha}$ & SE & $\hat{\alpha}$ & SE & $\hat{\alpha}$ & SE \\
\hline Bel. & 0.48 & 0.09 & 0.48 & 0.09 & 0.48 & 0.09 & 0.55 & 0.09 & 0.58 & 0.09 & 0.55 & 0.09 \\
\hline Den. & 0.50 & 0.09 & 0.50 & 0.09 & 0.50 & 0.09 & 0.47 & 0.09 & 0.47 & 0.09 & 0.47 & 0.09 \\
\hline Ger. & 0.36 & 0.08 & 0.36 & 0.08 & 0.36 & 0.08 & 0.42 & 0.09 & 0.42 & 0.09 & 0.41 & 0.09 \\
\hline Gr. & 0.64 & 0.10 & 0.70 & 0.10 & 0.64 & 0.10 & 0.59 & 0.10 & 0.60 & 0.10 & 0.61 & 0.10 \\
\hline Sp.n & 0.67 & 0.11 & 0.71 & 0.11 & 0.70 & 0.11 & 0.47 & 0.12 & 0.47 & 0.12 & 0.42 & 0.12 \\
\hline Fr. & 0.45 & 0.09 & 0.45 & 0.09 & 0.45 & 0.09 & 0.61 & 0.09 & 0.61 & 0.08 & 0.64 & 0.08 \\
\hline Ire. & 0.39 & 0.09 & 0.37 & 0.09 & 0.36 & 0.09 & 0.47 & 0.09 & 0.47 & 0.09 & 0.46 & 0.09 \\
\hline Ital & 0.67 & 0.08 & 0.67 & 0.08 & 0.68 & 0.08 & 0.64 & 0.08 & 0.64 & 0.08 & 0.64 & 0.08 \\
\hline Lux. & 0.46 & 0.10 & 0.45 & 0.10 & 0.46 & 0.10 & 0.42 & 0.10 & 0.39 & 0.10 & 0.41 & 0.10 \\
\hline Neth. & 0.42 & 0.09 & 0.41 & 0.09 & 0.42 & 0.09 & 0.52 & 0.09 & 0.54 & 0.09 & 0.52 & 0.09 \\
\hline Port. & 0.50 & 0.12 & 0.50 & 0.12 & 0.50 & 0.12 & 0.65 & 0.12 & 0.65 & 0.12 & 0.69 & 0.11 \\
\hline UK & 0.42 & 0.09 & 0.42 & 0.09 & 0.41 & 0.09 & 0.30 & 0.08 & 0.30 & 0.08 & 0.30 & 0.08 \\
\hline EU & 0.42 & 0.09 & 0.42 & 0.09 & 0.41 & 0.09 & 0.39 & 0.09 & 0.35 & 0.08 & 0.39 & 0.08 \\
\hline
\end{tabular}

Note: Estimates are based on $D=1$, where the instrument is the constant, $D=2$ (fe), where the instruments are the constant and the lagged forecast error, and $D=3(\operatorname{tr})$, where the instruments are the constant and the lagged realization.

Table C.I. Size of $t$-test (nominal size 5\%) under skew-normal $\lambda=5$

\begin{tabular}{lrlllll}
\hline \multicolumn{7}{c}{ (A) Instruments: constant } \\
\hline$n_{0}$ & \multicolumn{7}{c}{0} & 0.5 & 0.6 & 0.8 \\
\hline 50 & $n_{f}$ & 0.2 & 0.4 & 0.0476 & 0.0620 & 0.0650 \\
50 & 50 & 0.0760 & 0.0618 & 0.0456 & 0.0498 & 0.0660 \\
100 & 100 & 0.0692 & 0.0468 & 0.0430 & 0.0554 & 0.0702 \\
100 & 50 & 0.0868 & 0.0652 & 0.0446 & 0.0540 & 0.0772 \\
100 & 100 & 0.0656 & 0.0518 & 0.0424 & 0.0560 & 0.0542 \\
\hline
\end{tabular}


Table C.I. (Continued)

(B) Instruments: constant, lagged forecast error

\begin{tabular}{lrlllll}
\hline$n_{0}$ & $n_{f}$ & 0.2 & 0.4 & 0.5 & 0.6 & 0.8 \\
\hline 50 & 50 & 0.1158 & 0.0760 & 0.0658 & 0.0772 & 0.1282 \\
50 & 100 & 0.0928 & 0.0594 & 0.057 & 0.0662 & 0.0886 \\
100 & 50 & 0.1314 & 0.0796 & 0.0686 & 0.0758 & 0.1298 \\
100 & 100 & 0.0878 & 0.0592 & 0.0582 & 0.0622 & 0.0920 \\
100 & 200 & 0.0686 & 0.0548 & 0.0528 & 0.0518 & 0.0690
\end{tabular}

(C) Instruments: constant, lagged forecast error, lagged realized variable

\begin{tabular}{lrlllll}
\hline$n_{0}$ & $n_{f}$ & 0.2 & 0.4 & 0.5 & 0.6 & 0.8 \\
\hline 50 & 50 & 0.1888 & 0.0856 & 0.097 & 0.0898 & 0.1882 \\
50 & 100 & 0.1266 & 0.0656 & 0.0676 & 0.0648 & 0.1344 \\
100 & 50 & 0.1868 & 0.0984 & 0.0894 & 0.1052 & 0.2124 \\
100 & 100 & 0.1232 & 0.0672 & 0.071 & 0.0674 & 0.1162 \\
100 & 200 & 0.0832 & 0.0566 & 0.0522 & 0.0528 & 0.053 \\
\hline
\end{tabular}

Note: $\lambda$ denotes the shape parameter of skew-normal, $n_{0}$ is the size of initial sample for the recursive estimation of regression parameters, $n_{\mathrm{f}}$ is the sample size used to estimate $\alpha .0 .2,0.4, \ldots 0.8$ are values for the true $a$ parameter.

Table C.II. Size of $t$-test (nominal size 5\%) under skew-normal $\lambda=-5$

\begin{tabular}{|c|c|c|c|c|c|c|}
\hline \multicolumn{7}{|c|}{ (A). Instruments: constant } \\
\hline$n_{0}$ & $n_{f}$ & 0.2 & 0.4 & 0.5 & 0.6 & 0.8 \\
\hline 50 & 50 & 0.0668 & 0.0568 & 0.0432 & 0.0648 & 0.0706 \\
\hline 50 & 100 & 0.0714 & 0.0498 & 0.0422 & 0.0532 & 0.0692 \\
\hline 100 & 50 & 0.0698 & 0.0554 & 0.0428 & 0.0556 & 0.0690 \\
\hline 100 & 100 & 0.0666 & 0.0574 & 0.0466 & 0.0522 & 0.0640 \\
\hline 100 & 200 & 0.0504 & 0.0560 & 0.0472 & 0.0540 & 0.0542 \\
\hline \multicolumn{7}{|c|}{ (B). Instruments: constant, lagged forecast error } \\
\hline$n_{0}$ & $n_{f}$ & 0.2 & 0.4 & 0.5 & 0.6 & 0.8 \\
\hline 50 & 50 & 0.1294 & 0.0738 & 0.0676 & 0.0740 & 0.1420 \\
\hline 50 & 100 & 0.0992 & 0.0552 & 0.0564 & 0.0542 & 0.0870 \\
\hline 100 & 50 & 0.1324 & 0.0740 & 0.0732 & 0.0694 & 0.1310 \\
\hline 100 & 100 & 0.0884 & 0.0546 & 0.0586 & 0.0632 & 0.0878 \\
\hline 100 & 200 & 0.0710 & 0.0520 & 0.0552 & 0.0534 & 0.0664 \\
\hline
\end{tabular}

(C). Instruments: constant, lagged forecast error, lagged realized variable

\begin{tabular}{lrccccc}
\hline$n_{0}$ & $n_{f}$ & 0.2 & 0.4 & 0.5 & 0.6 & 0.8 \\
\hline 50 & 50 & 0.0310 & 0.0496 & 0.0474 & 0.0458 & 0.0338 \\
50 & 100 & 0.0508 & 0.0548 & 0.0456 & 0.0490 & 0.0432 \\
100 & 50 & 0.0370 & 0.0562 & 0.0540 & 0.0446 & 0.0284 \\
100 & 100 & 0.0466 & 0.0528 & 0.0492 & 0.0514 & 0.0430 \\
100 & 200 & 0.0536 & 0.0498 & 0.0524 & 0.0520 & 0.0526 \\
\hline
\end{tabular}

Note: $\lambda$ denotes the shape parameter of skew-normal, $n_{0}$ is the size of initial sample for the recursive estimation of regression parameters, $n_{\mathrm{f}}$ is the sample size used to estimate $\alpha .0 .2,0.4, \ldots 0.8$ are values for the true $a$ parameter. 


\section{REFERENCES}

Arnold BC, Lin GD. 2004. Characterizations of the skew-normal and generalized chi distributions, Sankhyã. The Indian Journal of Statistics 66(4): 593-606.

Artis M. 1996. How accurate are the IMF's short-term economic forecasts? Another examination of the World Economic Outlook. IMF working paper, WP/96/89, August.

Artis M, Marcellino M. 2001. Fiscal forecasting: the track record of the IMF, OECD and EC. Econometrics Journal 4: S20-36.

Bachelor R, Peel D. 1998. Rationality testing under asymmetric loss. Economics Letters 61(1): 49-54.

Brown SJ, Goetzmann WN, Ross SA. 1995. Survival. Journal of Finance 50(3): 853-873.

Christodoulakis GA. 2005. Financial forecasts in the presence of asymmetric loss aversion, skewness and excess kurtosis. Finance Research Letters 2(4): 227-233.

Christodoulakis GA. 2006. Hubris hypothesis and the reciprocity of preferences and densities in optimal forecast decisions. SSRN working paper. http://ssrn.com/abstract=946325 [1 January 2009].

Danthine JP, Donaldson J. 1999. Non-falsified expectations and general equilibrium asset pricing: the power of the Peso. Economic Journal 109: 607-635.

Donald SG, Newey WK. 2001. Choosing the number of instruments. Econometrica 69: 1161-1192.

Elliott G, Komunjer I, Timmermann A. 2005. Estimation and testing of forecast rationality under flexible loss. Review of Economic Studies 72: 1107-1125.

Goetzmann W, Jorion P. 1999a. Global stock markets in the twentieth century. Journal of Finance 54: 953-980.

Goetzmann W, Jorion P. 1999b. Re-emerging markets. Journal of Financial and Quantitative Analysis 34(1): $1-32$.

Hansen L, Singleton L. 1982. Generalised instrumental variables estimation of nonlinear rational expectations models. Econometrica No. 50: 714-735.

Lars J, Larch M. 2006. Improving fiscal policy in the EU: the case for independent forecast. Economic Policy 21(47): 491-534.

Keereman F. 1999. The track record of the Commission forecasts. Economic Papers No. 137, European Commission, Brussels.

Kenen P, Schwarz A. 1986. An assessment of macroeconomic forecasts in the International Monetary Fund's World Economic Outlook. Working Papers in International Economics, Princeton University, International Finance Section.

Rietz TA. 1988. The equity risk premium: a solution. Journal of Monetary Economics 22: 117-131.

Roeger W, in't Veld J. 1997. QUEST II, a multi country business cycle and growth model. Economic Papers No. 123 European Commission, Directorate-General for Economic and Financial Affairs.

Veronesi P. 2004. The Peso problem hypothesis and stock market returns. Journal of Economic Dynamics and Control 28: $707-725$. 